Purdue University Purdue e-Pubs

$1-1-2008$

\title{
Cross-Section of Option Returns and Volatility
}

Amit Goyal

Emory University

Alessio Saretto

Purdue University

Follow this and additional works at: http:// docs.lib.purdue.edu/ciberwp

Goyal, Amit and Saretto, Alessio, "Cross-Section of Option Returns and Volatility" (2008). Purdue CIBER Working Papers. Paper 55. http://docs.lib.purdue.edu/ciberwp/55

This document has been made available through Purdue e-Pubs, a service of the Purdue University Libraries. Please contact epubs@purdue.edu for additional information. 


\section{Cross-Section of Option Returns and Volatility}

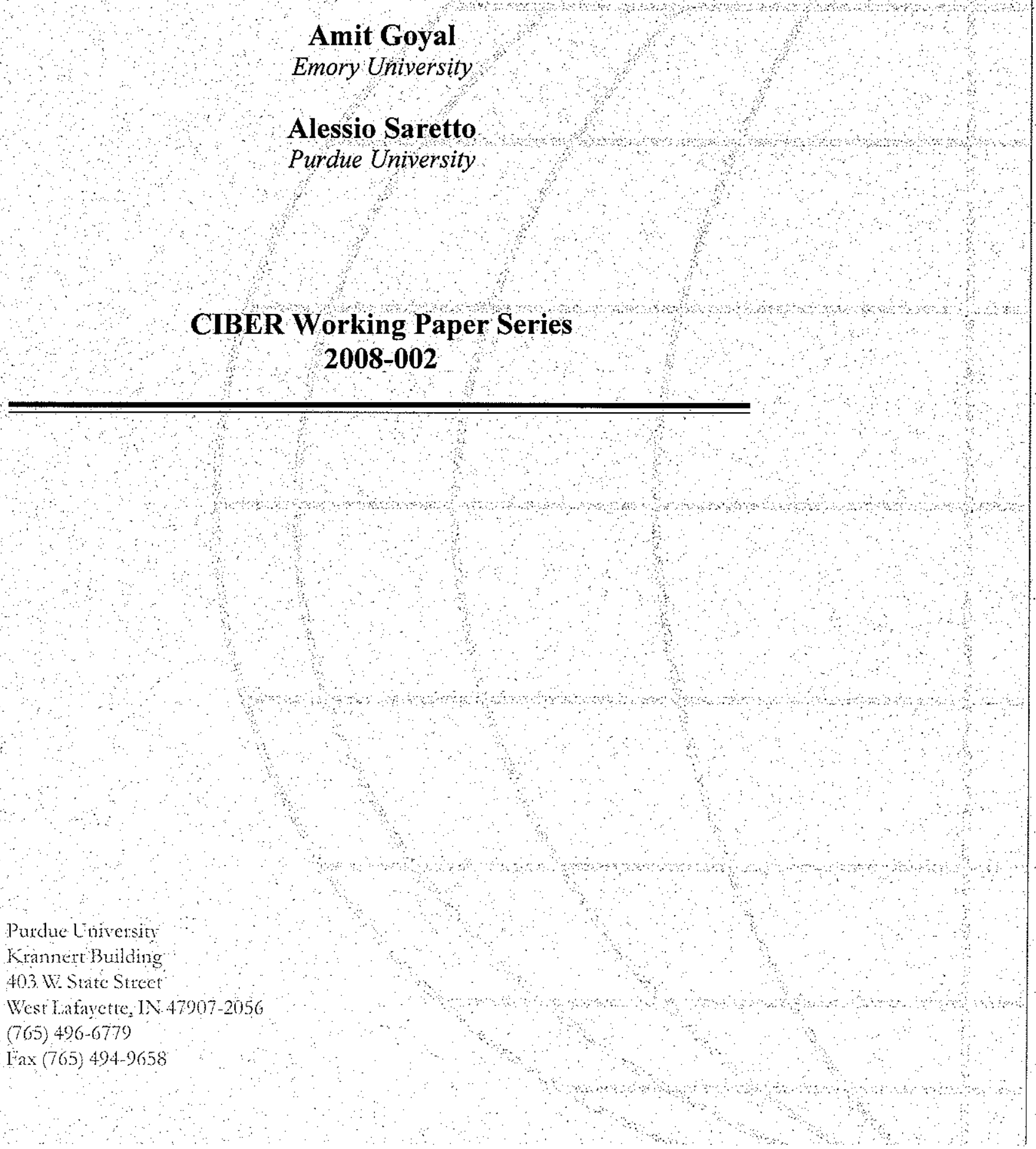




\title{
Cross-Section of Option Returns and Volatility*
}

\author{
Amit Goyal \\ Goizueta Business School \\ Emory University ${ }^{\dagger}$
}

\author{
Alessio Saretto \\ The Krannert School \\ Purdue University ${ }^{\ddagger}$
}

March 2008

\begin{abstract}
We study the cross-section of stock option return by constructing decile portfolios of straddles and delta-hedged calls and puts based on sorting stocks on the difference between historical realized volatility and at-the-money implied volatility. We find that a zero-cost trading strategy that is long (short) in the portfolio with a large positive (negative) difference between these two volatility measures produces an economically and statistically significant average monthly return. The results are robust to different market conditions, to stock risks-characteristics, to various industry groupings, to option liquidity characteristics, and are not explained by usual risk factor models.
\end{abstract}

JEL Classifications: C21, G13, G14

*We thank Tarun Chordia, Robert Dittmar, Darrell Duffie, Bernard Dumas, Andrea Frazzini, Laura Frieder, Robert Geske, Raffaella Giacomini, Mark Grinblatt, Narasimhan Jegadeesh, John McConnell, Richard Roll, Pedro Santa-Clara, Elena Sernova, Jay Shanken, Walter Torous, and the seminar participants at Emory University, Erasmus University, HEC Lausanne, Purdue University, Simon Fraser University, Tilburg University, UCLA, University of Illinois Urbana-Champaign, University of Kansas, University of Michigan, Virginia Tech, and Swiss Finance Institute conference on Portfolio Management and Derivatives for valuable suggestions. Alessio Saretto gratefully acknowledge financial support from the Purdue CIBER center. The usual disclaimer applies.

${ }^{\dagger}$ Atlanta, GA 30322, phone: (404) 727-4825, e-mail: amit_goyal@bus.emory.edu.

${ }^{\ddagger}$ West Lafayette, IN 47907, phone: (765) 496-7591, e-mail: asaretto@purdue.edu. 


\section{Introduction}

Options allow an investor to have a view about the underlying security price and volatility. A successful option trading strategy must rely on a signal about at least one of these inputs. In the vernacular of option traders, at the heart of every "volatility trade" lies the trader's conviction that the market expectation about future volatility, which is implied by the option price, is somehow not correct. Since all the option pricing models require at least an estimate of the parameters that characterize the probability distribution of future volatility, volatility mis-measurement is the most obvious source of options mispricing.

A common finding reported by studies of measurement and forecasting volatility is mean-reversion: volatility tends to revert to its long-run historical average. ${ }^{1}$ Any forecast of future volatility must account for this mean-reversion. One such forecast is embedded in the implied volatility (IV) of the stock, which can be obtained by inverting an option pricing model such as the Black and Scholes (1973) model. ${ }^{2}$ Therefore, IV from an option on a stock should reflect the fact that future volatility will, on average, be closer to its HV than to its current volatility. In other words, large deviations of IV from HV are indicative of mis-estimation of mean reversion in volatility, possibly due to over-reaction to current information. Of course, mean-reversion does not imply that, at any point in time, IV should be close to $\mathrm{HV}$, or that $\mathrm{HV}$ is the best estimate of future volatility. In fact, the stochastic nature of volatility and the existence of a volatility risk premium necessarily results in differences between IV and HV. Our conjecture is only that large deviations of IV from $\mathrm{HV}$ are indicative of mis-estimation of mean reversion in volatility.

We, therefore, sort stocks into deciles based on the difference between $\mathrm{HV}$ and IV. $\mathrm{HV}$ is calculated using the standard deviation of daily realized stock returns over the most recent twelve months and IV is obtained from one month to maturity, at-the money (ATM) options. In order to partially limit measurement errors, we compute the stock's IV by taking the average of the ATM call and put implied-volatilities. This also ensures that we construct a homogeneous sample with respect to the options' contract characteristics across stocks, and that we consider the most liquid options contracts for each stock.

\footnotetext{
${ }^{1}$ The volatility forecasting literature is extensive and too voluminous to cite in detail here. The interested reader is referred to the recent surveys in Granger and Poon (2003) and Andersen, Bollerslev, Christoffersen, and Diebold (2006).

${ }^{2}$ Strictly speaking, IV is only a rough estimate of the market's risk-neutral estimate of future volatility of the underlying asset. Britten-Jones and Neuberger (2000) derive a procedure that gives the correct estimate of the option-implied (i.e. risk-neutral) integrated variance over the life of the option contract when prices are continuous but volatility is stochastic. Jiang and Tian (2005) improve upon this procedure and also show it's validity in a jump-diffusion setting.
} 
Having sorted the stocks we form an option portfolio for each group. We calculate equallyweighted monthly portfolio returns of straddles and delta-hedged calls/puts on stocks in each decile. Since both of these strategies have a low delta, they have very little directional exposure to the underlying stocks.

We find that a zero-cost trading strategy involving a long position in a portfolio of options with a large positive difference between HV and IV and a short position in a portfolio of options with a large negative difference generates statistically and economically significant returns. For example, a long-short portfolio of straddles yields a monthly average return of $22.5 \%$ and a Sharpe ratio of 0.718 . These returns are comparable to those in Coval and Shumway (2001), who report absolute returns of around $3 \%$ per week for zero-beta straddles on the S\&P 500. Similarly, we find statistically and economically significant positive returns for high decile portfolios and negative returns for low decile portfolios of delta-hedged calls and puts.

We then examine whether returns to the long-short strategy are related to aggregate risk and/or characteristics. We consider the expected returns on delta-hedged positions in the model of Duarte and Jones (2007). This model provides guidance in thinking about $\beta$ 's for (instantaneous) option returns. We find that alphas from this framework are very close to raw returns. In fact, alphas from a more standard risk-factor model with standard equity-risk and option-risk factors are also very high. ${ }^{3}$ We also explore whether stock/option characteristics are related to the variation in our portfolio returns, by crosssectional regressions as well as via double sorted portfolios. Our analysis shows that, while the option returns covary with some of the stock characteristics that are found to be important for stock returns, this covariance is not enough to explain the high realized portfolio returns.

Our results are robust to choice of sample periods as well as volatility measures. We, consistent with the literature on transaction costs on options markets, find that trading frictions reduce the profitability of the option portfolio strategy. For instance, the longshort straddle portfolio returns are reduced to $7.5 \%$ per month if we consider trading options at an effective spread equal to the quoted spread. ${ }^{4}$ Consistent with the notion

\footnotetext{
${ }^{3}$ Although these regressions are linear factor models, we find that non-linear adjustments make virtually no difference. For instance, conditioning betas on option greeks or Leland (1999) model yields the no appreciable difference in alphas from standard alphas.

${ }^{4}$ De Fontnouvelle, Fisher, and Harris (2003) and Mayhew (2002) document that typically the ratio of effective to quoted spread is less than 0.5. On the other hand, Battalio, Hatch, and Jennings (2004) study two periods in the later part of the sample, January 200 and June 2002, and find that for a small sample of stocks the ratio of effective spread to quoted spread is around 0.8.
} 
that liquidity affects the implementation of portfolio strategies, we also find that the profits are higher for illiquid options than for liquid options. Our analysis, therefore, shows that liquidity considerations reduce, but do not eliminate, the economically important profits of our portfolios.

To further understand the underlying reasons of the empirical regularity that we observe, we study the behavior of volatility (IV and HV) around the portfolio formation date. We find that the deviations between these two measures are transitory. We also note that stocks in decile one (ten) have negative (positive) returns in the month preceding portfolio formation, and that the realized volatility of stocks in decile one (ten) increases after the portfolio formation date. Therefore, consistent with findings usually reported in the literature, IV predicts future realized volatility. However, we find that the change in future realized volatility is smaller in magnitude than what is implied by the IV at portfolio formation. These facts, therefore, suggest that investors over-react to current events in their estimation of future volatility. Our findings are analogous to those of Stein (1989). Stein studies the term structure of the implied volatility of index options and finds that investors overreact to the current information. They ignore the long-run mean reversion in implied volatility and instead overweight the current shortterm implied volatility in their estimates of long-term implied volatility. Our findings are also consistent with those of Poteshman (2001), who finds that investors in the options market over-react, particularly to periods of increasing or decreasing changes in volatility.

We reiterate that we cannot conclusively establish that our portfolio returns are abnormal, only that they are not related to obvious sources of risk. If, however, these returns are indeed abnormal, it is useful to consider why options are mispriced, especially given the significant size of the option market and the quality of option traders. ${ }^{5}$ We consider the possibility that economic agents do not use all the available information in forming expectations about future stock volatilities. In particular, they ignore the information contained in the cross-sectional distribution of implied volatilities and consider assets individually when forecasting volatility. This leads them to mis-estimate the mean reversion parameter in the underlying stochastic volatility and, therefore, to incorrectly price the option. To test this conjecture, we form alternative real-time estimates of implied volatil-

\footnotetext{
${ }^{5}$ The total volume of the equity options for the year 2004 was worth approximately 220 billion dollars. For comparison, the total volume of the S\&P 500 index options was worth about 120 billion dollars (see the Options Clearing Corporation 2004 annual report at http://www.optionsclearing.com/about/ann_rep/ann_rep_pdf/annual_rep_04.pdf). Evidence that options traders are sophisticated investors is reported by Easley, O'Hara, and Srinivas (1998), Pan and Poteshman (2006), and Ni, Pan, and Poteshman (2006) who show that options' volume contains information about future stock prices.
} 
ity using cross-sectional regressions. We use these alternative measures to recalculate option prices and find that these repriced options do not lead to excess returns.

Our paper is related to the growing recent literature that analyzes trading in options. Coval and Shumway (2001) and Bakshi and Kapadia (2003) study trading in index options. Chava and Tookes (2006), Ni, Pan, and Poteshman (2006) and Ni (2006) study the impact of news/information on trading in individual equity options. To the best of our knowledge, we are the first to study the economic impact of volatility mispricing through individual equity option trading strategies.

The rest of the paper is organized as follows. The next section discusses the data. Section 3 presents the main results of the paper by studying option portfolio strategies. Whether returns to option portfolios are related to fundamental risks and/or characteristics is investigated in Section 4. We present robustness checks as well as impact of trading frictions on portfolio profitability in Section 5. Section 6 presents a discussion of the results. We conclude in Section 7.

\section{Data}

The data on options are from the OptionMetrics Ivy DB database. The dataset contains information on the entire U.S. equity option market and includes daily closing bid and ask quotes on American options as well as their IV and greeks for the period from 1996 to 2005. The IVs and greeks are calculated using a binomial tree model using Cox, Ross, and Rubinstein (1979). ${ }^{6}$

We apply a series of data filters to minimize the impact of recording errors. First we eliminate prices that violate arbitrage bounds. Second we eliminate all observations for which the ask is lower than the bid, or for which the bid is equal to zero, or for which the spread is lower than the minimum tick size (equal to $\$ 0.05$ for option trading below $\$ 3$ and $\$ 0.10$ in any other cases). Third, to mitigate the impact of non-trading, we eliminate from the sample all the observations for which both the bid and the ask are equal to the previous day quotes or for which there is no volume.

We construct portfolios of options and their underlying stocks. These portfolios are

\footnotetext{
${ }^{6}$ Battalio and Schultz (2006) note that option and underlying prices are recorded at different times in the Ivy DB database, creating problems when an arbitrage relation such as the put-call parity is examined. This property of the data is not an issue for us because the tests that we conduct do not require perfectly coordinated trading data in the two markets.
} 
formed based on information available on the first trading day (usually a Monday) immediately following the expiration Saturday of the month (all the options expire on the Saturday immediately following the third Friday of the expiration month). In order to have a continuous time series with constant maturity, we consider only those options that mature in the next month. Among these options with one month maturity, we then select the contracts which are closest to ATM. Since it is not always possible to select options with moneyness (defined as the ratio of strike to stock price) exactly equal to one, we only keep options with moneyness between 0.975 and 1.025. We, thus, select an option contract which is close to ATM and expires next month for each stock each month. After next month expiration, a new option contract with the same characteristics is selected. Our final sample is composed of 32,589 monthly observations. The average moneyness for calls and puts is very close to one. There are 2,919 stocks in the sample for which it is possible to construct at least one IV observation.

For each stock each month, we calculate two different measures of volatility. Historical volatility $(\mathrm{HV})$ is calculated using the standard deviation of realized daily stock returns over the most recent twelve months. Implied volatility (IV) is computed by taking the average of the ATM call and put implied-volatilities. We first compute the time-series average of these volatilities for each stock and then report the cross-sectional average of these average volatilities in Table 1 . The other statistics are computed in a similar fashion so that the numbers reported in the table are the cross-sectional averages of the time-series statistics and can be interpreted as the summary statistics on an 'average' stock.

Both HV and IV are close to each other, with values of $60.4 \%$ and $58.4 \%$, respectively. The overall distribution of IV is, however, more volatile and more positively skewed than that of HV. The average monthly change in both measures of volatility is very close to zero. Changes in IV can be quite drastic and usually correspond to events of critical importance for the survival of a firm. For example, UICI, a health insurance company, has a $\Delta \mathrm{IV}$ of $86 \%$ which corresponds to the release of particularly negative quarter loss for the fourth quarter of 1999. During the month of December, UICI options went from trading at an ATM IV of $31 \%$ to an IV of $117 \%$. The stock price lost $56 \%$ of its value in the same month. Many of the other large spikes in volatility happen during months of large declines in stock prices. For example, the IV of the stocks in the technology sector jumped over $150 \%$ during the burst of the Nasdaq bubble in the spring of 2000. Spikes in individual stock IV also happen on earnings announcements (Dubinsky and Johannes $(2005))$. 
Individual equity options share some characteristics with index options, which have been the primary subject of prior research. Figure 1 plots the time series of VIX (implied volatility index that measures the markets expectation of 30-day S\&P500 volatility implicit in the prices of near-term S\&P500 options) and the time series of the cross-sectional average IV. Naturally, the level of IV is much higher than that of VIX. Both series have spikes that correspond to important events, such as the Russian crisis of September 1998. The two variables are also highly correlated. The correlation coefficient of the changes in VIX and changes in equal-weighted (value-weighted) average IV is 67\% (82\%).

\section{Option Portfolio Strategies}

All option pricing models require, at least, an estimate of the parameters that characterize the probability distribution of future volatility. It is well known that volatility is highly mean-reverting - the average autocorrelation for individual stock volatility in our sample is 0.7 . This implies that large deviations of current volatility from its long-term average are temporary in nature and are likely to reduce in magnitude at a quick rate (determined by the mean-reversion parameter). Any forecast of future volatility must account for this mean-reversion. One such forecast is embedded in the IV of the stock. Therefore, IV from an option on a stock should reflect the fact that future volatility will, on average, be closer to its $\mathrm{HV}$ than to its current volatility. In other words, large deviations of IV from $\mathrm{HV}$ are indicative of mis-estimation of mean reversion in volatility. Our conjecture on volatility mispricing, possibly due to mis-estimation of mean-reversion parameters, is closely related to the findings for index options reported in Stein (1989). Stein finds that investors ignore the long-run mean reversion in implied volatility and instead overweight the current short-term implied volatility in their estimates of long-term implied volatility. ${ }^{7}$

Note that we are not suggesting that mean-reversion implies that IV should be the same as realized (historical or current) volatility. Indeed the stochastic nature of volatility and the existence of a volatility risk premium necessarily results in differences between IV and HV. ${ }^{8}$ However, high autocorrelation of volatility implies that large deviations between IV and HV are unlikely to persist. We, therefore, speculate that if there is volatility

\footnotetext{
${ }^{7}$ Poteshman (2001) also finds evidence of overreaction in the index options market.

${ }^{8}$ On one hand, deviations of IV from HV will be more pronounced for stocks with higher volatility of volatility than for stocks with lower volatility of volatility. On the other hand, stocks with high prices of volatility risk (positive or negative) will also exhibit differences between IV and (future) realized volatility: IV is in fact only the risk-neutral expectation of future volatility. We discuss this point in greater detail in Section 6.3.
} 
mispricing then it is more likely to manifest itself in extreme temporary deviations between HV and IV. Stocks for which IV is much lower than HV have cheap options, and stocks for which IV is much higher than HV have expensive options. We sort stocks into portfolios based on the difference between these two volatility estimates and calculate returns on options in these portfolios.

\subsection{Portfolios Descriptives}

We sort stocks into deciles based on the log difference between HV and IV. Decile ten consists of stocks with the highest (positive) difference while decile one consists of stocks with the lowest (negative) difference between these two volatility measures. We start our analysis by giving descriptive statistics on these deciles in Table 2. All statistics are first averaged across stocks in each decile to obtain portfolio statistics. The table reports the monthly averages of the continuous time-series of these portfolio statistics. On average, the portfolios contain 30 stock options in each month.

While HV generally increases as one proceeds from decile one to decile ten, IV follows the opposite pattern decreasing from decile one to ten. Another illustration of the same phenomenon is the call/put prices scaled by the stock price (last two rows of Table 2). Since all our options are close to ATM, differences in the ratio of option price to underlying price are directly related to the differences in IV - options in decile one are more expensive than those in decile ten. We note that the spread in HV between portfolio one and ten is much larger than that in IV. This shows that our sort is not just on the levels on IV but on richer dynamics of the difference between $\mathrm{HV}$ and IV.

In unreported results, we also find a positive (negative) difference in decile one (ten) between IV in the portfolio formation month and the average IV over the previous twelve months. Therefore, the deviations of HV from IV are higher in the portfolio formation month than those in the prior months. In other words, portfolio formation month represents the month in which the IV of options in decile ten (one) increased (decreased) over its normal level relative to $\mathrm{HV}$.

There is not much variation (not accounted for by differences in IV's and underlying prices) in option greeks across deciles. For instance, deltas of calls in all deciles are close to 0.54 while the deltas of puts in all deciles are close to -0.47 . The gammas (second derivative with respect to underlying price) and vegas (first derivative with respect to volatility) are of similar magnitude across deciles. We also calculate the volatility of 
volatility $(\omega)$ as the standard deviation of changes in daily implied volatilities during the last six months, and the correlation between stock returns and innovations to volatility $(\rho)$ as the correlation between daily changes in implied volatility and stock returns over the last six months. We find that $\omega$ is higher for extreme portfolios than that for middle portfolios. This result is not surprising since larger deviations of IV from HV (longterm average of volatility) are more likely for those stocks with higher $\omega$. Whether this difference in the levels of $\omega$ has any systematic impact on the returns of the portfolios, however, depends on the sensitivity of these portfolios to risk factors. We discuss this issue later in the paper. Finally, we find that $\rho$ is less negative for the first two deciles but shows no appreciable pattern thereafter.

In unreported results, we find that there is no industry over-concentration in any of our portfolios deciles. We do find that stocks in our sample are typically large and belong to the top two deciles of market capitalization by NYSE breakpoints. For example, the average market capitalization of a stock in decile one (ten) is $\$ 5.8$ (\$7.4) billion, although there is no pattern in size across the deciles. Finally, we find that the skewness and kurtosis of stock returns is higher for higher numbered deciles than it is for lower numbered deciles.

\subsection{Portfolio Returns}

We construct time series of calls and puts returns for each stock in the sample. Recall that we do not include stale quotes in our analysis (we eliminate from the sample all the observations for which both the bid and the ask are equal to the previous day quotes). To further ameliorate microstructure biases, we also initiate option portfolio strategies on the second (Tuesday), as opposed to the first (Monday), trading day after the expiration Friday of the month. In other words, we start trading a day after the day that we obtain the signal (the difference between HV and IV). The returns are constructed using, as a reference beginning price, the average of the closing bid and ask quotes and, as the closing price, the terminal payoff of the option depending on the stock price at expiration and the strike price of the option. ${ }^{9}$ After expiration the next month, a new option with the same characteristics is selected and a new monthly return is calculated. Prices and returns for the underlying stock are taken from the CRSP database. Equally-weighted monthly returns on options in each portfolio are computed and the procedure is then repeated for

\footnotetext{
${ }^{9}$ The options are American. We, however, ignore the possibility of early exercise in our analysis for simplicity. Optimal early exercise decisions would bias our results downwards for the long positions in portfolio and upwards for the short positions in portfolios. The net effect is not clear. See Poteshman and Serbin (2003) for a discussion of early exercise behavior.
} 
every month in the sample.

Since our interest is in studying returns on options based only on their volatility characteristics, we want to neutralize the impact of movements in the underlying stocks. We accomplish this by forming straddle portfolios and delta-hedged portfolios. The straddle portfolios are formed as a combination of one call and one put. ${ }^{10}$ For delta-hedged portfolios, we use the delta (based on the current IV) provided to us by the IVY database. ${ }^{11,12}$

Table 3 reports the returns on these option portfolios. In addition to standard descriptive statistics, we also calculate two measures related to the risk-return trade-off for the portfolios: Sharpe ratio (SR) and certainty equivalent (CE). CE is computed for a long position in the portfolio and is constructed using a power utility with a coefficient of relative risk aversion, $\gamma$, equal to three and seven. SR is the most commonly used measure of risk-return trade-off, but CE is potentially a better measure than SR because it takes into account all the moments of the return distribution.

Panel A of Table 3 shows that straddle portfolios exhibit a striking pattern with returns that go from $-9.9 \%$ to $12.6 \%$ respectively. The volatility of the straddle portfolios is also low at between $20 \%$ and $34 \%$ per month. The long-short straddle strategy has an average return of $22.5 \%$ with a $31.4 \%$ monthly standard deviation (the minimum monthly return in the sample is $-40.5 \%)$, leading to a monthly $\mathrm{SR}$ of 0.718 and a $\mathrm{CE}(\gamma=3)$ of $11.1 \%$ per month. To put all these numbers in perspective, the value-weighted CRSP portfolio has a monthly SR of 0.111 and a monthly CE of $0.488 \%(\gamma=3)$ for our sample period.

The magnitude of returns for delta-hedged calls (Panel B) and puts (Panel C) is lower than that for straddles, as is to be expected. However, we see that our sorting criterion still lends itself to positive returns for high decile portfolios and negative returns for low decile portfolios. The long-short 10-1 portfolio returns for delta-hedged calls (puts) are

\footnotetext{
${ }^{10}$ In addition to the simple straddle returns, we also considered zero-delta and zero-beta straddles. Zero-delta straddles were formed using the delta provided by the IVY database, while zero-beta straddles were constructed following the procedure in Coval and Shumway (2001). The returns on these portfolios were very similar to the ones reported in the paper for the plain vanilla straddles.

${ }^{11}$ If there is volatility mispricing in options, a more powerful and profitable approach is to recalculate delta based on an implied volatility estimate. We, however, do not attempt to estimate a new delta because we do not have an alternative estimate of implied volatility (only a signal that IV is higher/lower than HV). Green and Figlewski (1999) note that a delta-hedged strategy based on incorrect delta entails risk and does not provide a riskless rate of return. This means that we are conservative in our construction of delta-hedged portfolios - we earn lower returns and have higher risk.

${ }^{12}$ Our delta-hedged portfolios are held until expiration and not rebalanced during the holding period (similar to the straddle portfolios). This is a conservative approach as our buy-and-hold strategy entails higher risk than a frequently/daily rebalanced strategy. Note, however, that rebalancing the portfolio would involve transaction costs of trading the underlying stock to adjust the delta.
} 
$2.7 \%(2.6 \%)$ with standard deviations of $4.4 \%(3.8 \%)$. The low standard deviation of these portfolios leads to high SRs. For instance, SR for long-short call (put) delta-hedged portfolio is $0.612(0.676)$. The absence of huge positive and negative returns also leads to positive CEs.

Note that these option returns do not appear to be driven by directional exposure to the underlying asset. When underlying stocks are sorted according to the same portfolio classification, the returns of the stock portfolios exhibit no pattern across deciles. Moreover, since the deltas of all long-short option portfolios are close to zero (see Table 2), even with an average stock volatility of $50 \%$, a return of $0.2 \%$ for the long-short stock portfolio is unlikely to account for the magnitude of the option portfolios. ${ }^{13}$

\section{Controls for Risk and Characteristics}

Our next task is to establish whether the large portfolio returns are systematic compensation for risk or abnormal. Since options are derivative securities, it is reasonable to assume that option returns depend, at least, on the same sources of risks or characteristics that explain individual stock returns. The absence of a general formal theoretical model for the cross-section of option returns, however, makes our endeavor non-trivial. We approach our problem from several different perspectives. We start by considering the expected returns on delta-hedged positions in the model of Duarte and Jones (2007). This model, although stylized, provides guidance in thinking about $\beta$ 's for (instantaneous) option returns. We use this model to compute theoretically expected returns and compare them to realized returns and obtain an alpha in this framework. Next, we take the spirit of the model to run factor-model regressions with the standard equity-risk factors augmented with riskfactors for options. Finally, we explore whether stock/option characteristics are related to the variation in our portfolio returns. This final analysis is done on individual options via cross-sectional regressions, as well as via double sorted portfolios. We acknowledge that we (like others) are subject to joint hypothesis problem - the estimated 'alphas' are derived from models and, therefore, rejection of the null of zero alpha is a joint rejection

\footnotetext{
${ }^{13}$ In unreported results, we find that the portfolios constructed by sorting on the levels of HV or IV do not produce the same patterns in average returns even though these levels are on average related to our signal of the difference between HV and IV (see Table 2). While it is in general true that option portfolios of stocks with low realized volatility/high implied volatility (similar to decile one in Table 3) exhibit lower average returns than portfolios of stocks with high realized volatility/low implied volatility (similar to decile ten in Table 3), average returns for the long-short portfolios are often economically small and not statistically significant.
} 
of zero alphas and the model. Our hope is that these experiments taken together lend credence to our belief that the portfolio returns from previous section are not related to obvious sources of risk and characteristics.

\subsection{Expected Returns}

This subsection draws heavily upon Duarte and Jones (2007) and the interested reader is referred to their paper for further details. Individual stock return and volatility dynamics are related to those of market through a simple factor model. Analytical expressions are then derived for expected instantaneous returns on derivative positions. To be concrete, assume that the stock returns and volatility follow the process:

$$
\begin{aligned}
\frac{d S_{t}}{S_{t}} & =\mu_{t} d t+\sigma_{t} d B_{1 t} \\
d \sigma_{t} & =\theta_{t} d t+\omega_{t} \rho d B_{1 t}+\omega_{t} \sqrt{1-\rho^{2}} d B_{2 t}
\end{aligned}
$$

where $B_{1}$ and $B_{2}$ are uncorrelated Brownian motions. Here, volatility of volatility is represented by $\omega$ and $\rho$ is the correlation between stock returns and volatility. We assume that the functional form of processes is the same for market and individual stocks (and suppress the superscripts in the above equations to reduce notational clutter). The relation between the Brownian motions for individual stocks $\left(d B^{i}\right)$ and market $\left(d B^{m}\right)$ is given by:

$$
\begin{aligned}
& d B_{1 t}^{i}=\xi_{11}^{i} d B_{1 t}^{m}+\xi_{12}^{i} d B_{2 t}^{m}+d Z_{1 t}^{i} \\
& d B_{2 t}^{i}=\xi_{21}^{i} d B_{1 t}^{m}+\xi_{22}^{i} d B_{2 t}^{m}+d Z_{2 t}^{i}
\end{aligned}
$$

where $\xi$ 's represent correlations between Brownian motions driving the processes for individual stocks and those for the market. Let $\lambda_{1}$ and $\lambda_{2}$ denote the prices of stock risk and volatility risk, respectively. Then it follows from the above equations that these two prices for individual securities are given by:

$$
\begin{aligned}
& \lambda_{1 t}^{i}=\xi_{11}^{i} \lambda_{1 t}^{m}+\xi_{12}^{i} \lambda_{2 t}^{m} \\
& \lambda_{2 t}^{i}=\xi_{21}^{i} \lambda_{1 t}^{m}+\xi_{22}^{i} \lambda_{2 t}^{m} .
\end{aligned}
$$

Let the price of a derivative be given by $f\left(S_{t}, \sigma_{t}, t\right)$ and consider a total delta-hedged

portfolio, $H$, with hedge ratio $n=-\left(\frac{\partial f}{\partial S}+\frac{\partial f}{\partial \sigma} \frac{\omega \rho}{\sigma S}\right)=-\left(\Delta+\nu \frac{\omega \rho}{\sigma S}\right)$. It can be shown that 
the excess return on this delta-hedged option is given by:

$$
E\left(\frac{d H_{t}^{i}}{H_{t}^{i}}\right)-r_{t} d t=\omega_{t}^{i} \sqrt{1-\rho^{i 2}} \lambda_{2 t}^{i} \frac{1}{f_{t}^{i}} \frac{\partial f^{i}}{\partial \sigma_{t}^{i}} d t
$$

The estimation of the last equation is facilitated by expressing the expected returns in a beta representation. If $\beta_{m t}^{i}$ and $\beta_{\sigma t}^{i}$ are the betas of scaled total delta-hedged portfolio with respect to market and market volatility factor, respectively, then

$$
\begin{aligned}
& \beta_{m t}^{i} \equiv \operatorname{cov}\left(\frac{\frac{d H^{i}}{H^{i}}}{\frac{1}{f^{i}} \frac{\partial f^{i}}{\partial \sigma^{i}}}, \frac{d S^{m}}{S^{m}}\right) / \operatorname{var}\left(\frac{d S^{m}}{S^{m}}\right)=\frac{\omega_{t}^{i} \sqrt{1-\rho^{i 2}} \xi_{21}^{i}}{\sigma_{t}^{m}} \\
& \beta_{\sigma t}^{i} \equiv \operatorname{cov}\left(\frac{\frac{d H^{i}}{H^{i}}}{\frac{1}{f^{i}} \frac{\partial f^{i}}{\partial \sigma^{i}}}, \frac{\frac{d H^{m}}{H^{m}}}{\frac{1}{f^{m}} \frac{\partial f^{m}}{\partial \sigma^{m}}}\right) / \operatorname{var}\left(\frac{\frac{d H^{m}}{H^{m}}}{\frac{1}{f^{m}} \frac{\partial f^{m}}{\partial \sigma^{m}}}\right)=\frac{\omega_{t}^{i} \sqrt{1-\rho^{i 2}} \xi_{22}^{i}}{\omega_{t}^{m} \sqrt{1-\rho^{m 2}}} .
\end{aligned}
$$

Substituting equations (3) and (5) into equation (4), we finally obtain:

$$
E\left(\frac{d H_{t}^{i}}{H_{t}^{i}}\right)-r_{t} d t=\frac{1}{f_{t}^{i}} \frac{\partial f_{t}^{i}}{\partial \sigma_{t}^{i}}\left(\beta_{m t}^{i} \sigma_{t}^{m} \lambda_{1 t}^{m}+\beta_{\sigma t}^{i} \omega_{t}^{m} \sqrt{1-\rho^{m 2}} \lambda_{2 t}^{m}\right) d t
$$

The last equation provides an analytical expression for instantaneous expected return on a total delta-hedged portfolio. We calculate the simple expected returns over an interval of a month by including a variance adjustment. The individual betas, $\beta_{m}^{i}$ and $\beta_{\sigma}^{i}$, are estimated by running a first-pass time-series regression over the whole sample of scaled delta-hedged returns on the market portfolio return and scaled delta-hedged market portfolio return, respectively. ${ }^{14}$ Market parameters are taken from Duarte and Jones (2007, Table 3). We report the betas, expected returns, actual returns, and the difference (alpha) for delta-hedged calls (puts) in Panel A (B) of Table 4.

While we find very little variation in $\beta_{\sigma}$ across deciles, $\beta_{m}$ is higher (less negative) for decile ten than it is for decile one. However, there is virtually no difference in expected returns across deciles. The realized returns, on the other hand, show a spread of $2.7 \%$ for calls and $2.6 \%$ for puts. Ergo, the abnormal returns (alphas) from this model are quite close to raw returns.

Moreover, to account for the fact that individual stock betas are likely going to be

\footnotetext{
${ }^{14}$ The analytical expressions are for total delta-hedged returns. We use plain vanilla delta-hedged returns in this analysis as Duarte and Jones (2007) show that this delta adjustment has an insignificant impact. The results are, however, virtually unchanged for total delta-hedged portfolios. Note also that we, like Duarte and Jones, assume that the parameters of the model are constant in the empirical implementation.
} 
time-varying, we repeat the previous exercise by considering conditional versions of market and volatility betas. As conditioning variables we use the stock's level and the market level (proxied by VIX) of implied volatility. Those modifications leave the results reported in Table 4 virtually unchanged.

It is useful at this stage to juxtapose these results with the values of $\omega$ (volatility of volatility) reported in Table 2. We know that the extreme portfolios have higher $\omega$. However, what matters for expected returns, as evidenced in equations (4) and (6), is the sensitivity of these portfolios to volatility risk, $\beta_{\sigma}$. Our portfolios show no variation in exposure to this risk. Consequently, there is almost no variation in expected returns across these portfolios, even though they have different levels of $\omega$.

\subsection{Risk Adjusted Returns}

We regress the long-short straddle and delta-hedged option portfolio returns on various specifications of a linear pricing model consisting of the Fama and French (1993) three factors, the Carhart (1997) momentum factor, and a volatility factor. This last factor for straddle portfolios is the Coval and Shumway (2001) aggregate volatility factor represented by the excess return on a zero-beta S\&P 500 index ATM straddle. ${ }^{15}$ For delta-hedged call (put) portfolios, we construct a similar delta-hedged market call (put) factor. Since all the factors are spread traded portfolios, the alpha intercept from the following regression can be interpreted in the usual sense of mispricing relative to the factor model:

$$
R_{p t}=\alpha_{p}+\beta_{p} F_{t}+e_{p t}
$$

The factor model considered here is an improvement over the previous subsection in two ways. One, inclusion of non-market factors (such as SMB, HML, and MOM) is a generalization of the market model. Second, since we run time-series regressions on portfolio returns, the estimation error of imprecisely estimated individual betas is reduced. However, any linear factor model is unlikely to characterize the cross-section of option returns over any discrete time interval. We use a linear model merely to illustrate that the option returns described in this paper are not related to aggregate sources of risk in an obvious way.

\footnotetext{
${ }^{15}$ We obtain data on the first four factors from Ken French's web site while we construct the straddle factor ourselves following the procedure described in Coval and Shumway (2001). During our sample period, the return on the zero-beta S\&P 500 index ATM straddle is $-10.3 \%$ per month.
} 
Estimated parameters for these factor regressions are reported in Table $5 .{ }^{16}$ The first regression shows that the straddle portfolio has a negative loading on the market factor. The second regression shows that the loadings on Fama and French factors are negative (although insignificant) and the loading on the momentum factor is positive (again insignificant). More interesting is the fact that the straddle portfolio loads positively on the zero-beta straddle portfolio. Since a common assumption is that the volatility risk premium is negative, this also implies that our positive portfolio returns are not a remuneration for volatility risk, but rather our portfolio is a good hedge for volatility risk. Regressions (3)-(6) show similar pattern for delta-hedged calls and puts, although none of the loadings are significant. ${ }^{17}$

We also make efforts to ameliorate the problem associated with linear factor models in two ways. First, we estimate the following factor-model regressions with conditional betas:

$$
R_{p t}=\alpha_{p}+\left(\beta_{0 p}+\beta_{1 p}^{\prime} \Theta_{t-1}\right)^{\prime} F_{t}+e_{p t}
$$

where $R$ is the return on portfolio, $F$ 's are factors, and $\Theta$ 's are portfolio option greeks (delta, gamma, and vega) and the level of aggregate implied volatility (as measured by VIX). Conditional betas are used to proxy for the time-variation (over the life of the option) in expected returns of options. The alphas from this model are very similar to those reported in Table 5. Second, we estimate Leland (1999) alpha. Leland proposes a correction to the linear factor models that allows the computation of a robust risk measure for assets with arbitrary return distributions. This measure is based on an equilibrium model in which a CRRA investor holds the market. Our estimate of Leland's alphas are also very close to the ones reported in Table 5. For instance, Leland alpha for straddle portfolio is equal to $23.5 \%$.

We have remarked earlier that the levels of skewness and kurtosis in stock returns are higher for decile ten than those for decile one. Are there differences in the sensitivity of portfolio returns to the risk of, rather than the levels of, higher moments? To explore this, we first run equation (7) including factors for skewness and kurtosis, such as the square and the cube of the market return, for each portfolio. ${ }^{18}$ We then take the betas

\footnotetext{
${ }^{16}$ Note that the betas in Table 5 are computed from unscaled returns while the betas in Table 4 are computed from scaled returns and are, therefore, not strictly comparable.

${ }^{17}$ We also tried to investigate whether liquidity risk factor can explain the option returns. However, we were unable to reconstruct the Pástor and Stambaugh (2003) or Sadka (2006) liquidity factors to exactly match our holding period (from Tuesday of the fourth week to the third Friday of the next month). When we used the misaligned factors in factor model regressions, we found that the loadings on these liquidity factors were not significant.

${ }^{18}$ See Kraus and Litzenberger (1976), Friend and Westerfield (1980), and Harvey and Siddique (2000)
} 
from these time-series regression and run a second stage cross-sectional regressions:

$$
\overline{R_{p}}-{\widehat{\beta_{1 p}}}^{\prime} \overline{F_{1}}={\widehat{\beta_{2 p}}}^{\prime} \lambda_{2}+\alpha_{p}
$$

where the bars denote the time-series sample averages, $\widehat{\beta_{1}}$ 's are loadings on traded factors, $\widehat{\beta_{2}}$ 's are loadings on non-traded factors, $\lambda_{2}$ 's are the prices of risks of non-traded factors, and the 'residuals' from the second-stage regression are the pricing errors. As a practical matter, we stack the first- and the second-stage regressions together in a GMM framework that allows us to account for the estimation error in betas in calculating the standard errors from the second-stage regression (see Cochrane (2001) for details on this procedure). We find that the betas on the non-traded factors are insignificant and the prices of risk $\left(\lambda_{2}\right)$ of these factors are also insignificant. Most important from our perspective, we find that alphas from this experiment are very close to the ones in Table 5.

Overall, our results indicate that the portfolio returns reported earlier are not explained by the usual risk factors. However, we advise caution in over interpreting this evidence. The joint hypothesis problem is especially acute for us since there are no models for expected option returns over discrete time periods. What seems unambiguous is that the option portfolio returns are not related to obvious sources of risks.

\subsection{Stock Characteristics}

We now investigate how the long-short straddle portfolio returns are related to equity characteristics. We first run cross-sectional regressions of risk-adjusted individual option returns on lagged characteristics. Specifically, our regressions specification is similar to that in Brennan, Chordia, and Subrahmanyam (1998):

$$
R_{i t}-\widehat{\beta}_{i}^{\prime} F_{i t}=\gamma_{0 t}+\gamma_{1 t}^{\prime} Z_{i t-1}+e_{i t}
$$

where $R$ is the return on options (in excess of risk-free rate), F's are factors, and $Z$ 's are

characteristics. The $\widehat{\beta}$ 's on the left-hand side of the equation are estimated via a first-pass time-series regression using the entire sample. The factors are the same as in Section 4.2. Besides the primary variable of interest (HV-IV), the other characteristics chosen are: size, book-to-market, past six-month return, skewness, and kurtosis. All characteristics are lagged by one month in regressions.

for studies relating skewness to stock returns. 
We run these regressions every month and report the time-series averages of $\gamma$ coefficients and their $t$-statistics in Table 6 . Consistent with results in prior sections, the difference between $\mathrm{HV}$ and IV is strongly statistically significant in explaining the pattern of subsequent returns. Size is the only stock characteristics that seem to have some predictive power for option returns. As there is a strong correlation between size and liquidity, this suggests an impact of liquidity for returns. We explore this in greater detail in Section 5.2.

We also investigated a bigger set of stock/option variables by including volatility of volatility $(\omega)$, proportion of systematic risk $\left(R^{2}\right)$, analyst forecast dispersion, and credit rating of the company's bonds. We select $\omega$ based on the evidence reported earlier in Table 2 which shows that $\omega$ is related to the difference between $\mathrm{HV}$ and IV, $R^{2}$ since Duan and Wei (2007) find that systematic risk proportion is useful for cross-sectionally explaining the prices of equity options, analyst dispersion because of the evidence in Diether, Malloy, and Scherbina (2002), and the credit rating to check if our option returns are related to default risk. Finally, two option characteristics (gamma and vega) are chosen to reflect information that is not directly contained in equities. The unreported results of these extensive experiments show that (1) none of these variables has predictive power for option returns, and (2) the difference between HV and IV remains strongly significant in each case.

To provide yet another perspective of whether characteristics subsume our effect, we consider two-way sorts - one based on the volatility signal (HV-IV) and the second based on characteristics. The advantage of this approach over the cross-sectional regressions is that it does not impose any linear structure of returns (the disadvantage is that we can only control for one characteristic at one time). We sort stocks into quintile portfolios, as opposed to deciles, to keep the portfolios well populated. Our sorts are conditional we first sort stocks into quintiles based on stock characteristics and, then, within each quintile, we sort stocks based on the difference between HV and IV. The five volatility portfolios are then averaged over each of the five characteristic portfolios. They, thus, represent volatility portfolios controlling for characteristics. Breakpoints for all stock characteristics are calculated each month based only on stocks in our sample. We report average return and the associated $t$-statistic of this continuous time-series of monthly portfolio returns for straddles, delta-hedged calls, delta-hedged puts in Panels A, B, and $\mathrm{C}$, respectively, of Table 7 . In all three panels, we find that the magnitude of returns is very similar across all controls. It ranges from $14 \%$ to $17.4 \%$ for straddles, and $1.5 \%$ to $2 \%$ to delta-hedged calls and delta-hedged puts. These numbers are also comparable to 
those in Table 3, albeit a bit lower as expected (since we sort into quintiles in Table 7 as opposed to deciles in Table 3).

We conclude that, while the option returns covary with some of the stock characteristics that are found to be important for stock returns, this covariance is not enough to subsume the predictive power of the difference between $\mathrm{HV}$ and IV in explaining option returns.

\section{Robustness and Trading Execution}

\subsection{Robustness}

The results in the previous sections are presented after we have made many choices about key variables and sample periods. In this section, we check whether our results our robust to these decisions. We only present the salient features of these tests to not overwhelm the readers with numbers (complete set of results can be obtained from us upon request).

\section{Moneyness}

We select options close to ATM with moneyness in the range 0.975-1.025. Our reason for choosing a narrow range of moneyness is that we do not want the option returns to be driven by the smile in the volatility surface. However, we check the sensitivity of our results by increasing the moneyness range to $0.95-1.05$. This leads to an increase in the number of overall stocks to 3,885 (from 2,919) and the average number of stocks in each decile portfolio to 110 (from 30). The volatility of the returns on the option portfolios also decreases as a consequence of greater number of stock options. However, the magnitude of raw returns and the alphas is very similar to that reported in the paper.

\section{Sub-sample returns}

We replicate the analysis of Table 3 by dividing the data into two sub-samples. The sub-samples are formed by considering two different states based on the sign of the changes in the VIX index and the sign of the market value-weighted CRSP portfolio returns. The conditional portfolio returns are higher in months in which VIX is increasing. For instance, the long-short straddle portfolio has returns of $28.9 \%$ in months of positive changes in VIX and $17.5 \%$ in months of negative changes in VIX. This pattern of returns also helps to explain the positive loading of long-short portfolio returns on options factors in Table 5. 
We obtain essentially the same result when we sort the sample based on market returns - option returns are higher in months of negative market returns. These two results are not completely independent since market returns and changes in VIX are negatively correlated.

When the sample is divided in the two sub periods 1996-2000 and 2001-2005 we observe that the average returns are statistically significant in both subsamples, although the average returns are higher for the period 1996-2000. Since the options market is particularly active during months in which the futures options expire ("triple witching Friday") we also compute the average return for the strategies in only those particular months and compare these to the returns in other months. We find that there is no statistically meaningful difference in portfolio returns across these two sets of months.

Figure 1 shows that the equity option market was particularly active during the years of the "technology bubble." It is, therefore, useful to establish if portfolio returns are high only in the technology industry. In unreported results, we find this not to be the case. The long-short straddle portfolio is quite profitable in each industry. The highest average return $(24.2 \%$ per month) is in the finance sector while the lowest return $(19.1 \%)$ is in the utilities industry. We also check if the distribution of industries is uniform across our volatility sorted deciles and find this to be the case.

\section{Volatility measures}

Our basic measure of IV is the average of one-month ATM call and put implied volatility. While it is necessary for us to calculate the IV using the same options (same moneyness/maturity) that we trade, it is still possible that the IV is biased in other ways. We check for this possibility by rerunning our analysis with two modifications. First, we calculate the IV using only the call or the put. Second, our options are American this implies that early exercise premium embedded in IV could make the IV measure not strictly comparable to HV. We check for this by removing all observations in which stock pays a dividend during the holding period. ${ }^{19}$ The results of both these experiments are virtually identical to those reported in the paper.

An alternative to the Black and Scholes implied volatility provided by IVY database is a model-free implied volatility (Jiang and Tian (2005)). This computation requires a large number of strikes for each stock at any point in time. The median number of strikes for options in our database is three. This implies that we can construct reliable estimates

\footnotetext{
${ }^{19}$ We acknowledge the fact that while this controls for early exercise option of calls, American puts might still have a premium.
} 
of model-free IV for a very small subset of stocks (for which there are at least ten strikes for each option). Our results are qualitatively similar for this restricted sample.

We calculate HV from daily stock return data. We do not use GARCH (or any versions, thereof) to estimate volatility as our purpose is not to forecast future volatility from calibrated models. We can use high-frequency intra-day data to potentially improve our measure of HV. However, unavailability of this data to us precludes us from doing this. Our hope is that there is no systematic bias in our use of daily data vis-à-vis intra-day data, especially since we calculate HV from a long time period of one year.

\section{Earnings announcements}

Dubinsky and Johannes (2005) find spikes in IV around earnings announcements. We check whether this influences our results again by running two tests. First, we remove observations where our trade dates coincide with earnings announcement dates (approximately $5 \%$ of observations). Second, we remove all observations where a company announces earnings during the month prior to portfolio formation date or during the holding period month. Removing these observations has no material impact on our results. In addition to the above tests, we find that the earning announcements are uniformly distributed in number across portfolios. Moreover, none of the portfolios show abnormally positive or negative earnings around these announcements - the standardized unexpected earnings measure shows no pattern across deciles.

\subsection{Transaction Costs}

There is a large body of literature that documents that transaction costs in the options market are quite large and are in part responsible for some pricing anomalies, such as violations of the put-call parity relation. ${ }^{20}$ It is essential to understand to what degree these frictions prevent an investor from exploiting the profits on the portfolio strategies studied in this paper. Therefore, in this section we discuss the impact of transaction costs, measured by the bid-ask spread and margin requirements, on the feasibility of the long-short strategy.

We consider the costs associated with executing the trades at prices inside the bid-ask spread. The results reported so far are based on returns computed using the mid-point price as a reference; however it might not be possible to trade at that price in every

\footnotetext{
${ }^{20}$ See for example Figlewski (1989), George and Longstaff (1993), Gould and Galai (1974), Ho and Macris (1984), Ofek, Richardson, and Whitelaw (2004), and Swidler and Diltz (1992).
} 
circumstance. De Fontnouvelle, Fisher, and Harris (2003) and Mayhew (2002) document that the effective spreads for equity options are large in absolute terms but small relative to the quoted spreads. Typically the ratio of effective to quoted spread is less than 0.5. On the other hand, Battalio, Hatch, and Jennings (2004) study a period in the later part of our sample (January 2000 to June 2002) and find that for a small sample of large stocks the ratio of effective spread to quoted spread fluctuates between 0.8 and 1 . Since transactions data is not available to us, we consider three effective spread measures equal to $50 \%, 75 \%$, and $100 \%$ of the quoted spread. In other words, we buy (or sell) the option at prices inside the spread. This is done only at the initiation of the portfolio since we terminate the portfolio at the expiration of the option.

Since the settlement of individual equity options require delivery of the underlying, we also include the transaction costs of trading the underlying stocks. In the case of the straddles, the cost is incurred only at expiration and it is relative to the shares that need to be bought or delivered as a consequence of the exercise of one of the two options. In the case of the delta-hedged strategies, shares of the underlying (for a quantity that depends on the option's delta) are bought or sold on the first trading day. At expiration of the option further costs are incurred to capitalize the gain/loss.

The stock trading costs are computed from two different sources. First, the effective spreads for each stock are computed using the intra-day TAQ data. ${ }^{21}$ In all cases where we are unable to obtain data from TAQ, we calculate effective spreads using the methodology of Hanna and Ready (2005). Hanna and Ready estimate effective bid-ask spreads for NYSE and AMEX stocks using transactions data. Then, they fit a regression model each year for the spreads using market capitalization, share price, monthly turnover and monthly volatility as independent variables. We refer the interested reader to their paper for further details.

Finally, to address the concern that the results might be driven by options that are thinly traded, we repeat the analysis by splitting the sample into two different liquidity groups. For each stock we compute the average quoted bid-ask spread and the daily average dollar volume of all the option contracts traded on that stock during the previous month. We then sort stocks into low and high liquidity groups, based on these characteristics, and calculate average returns and $t$-statistics for the long-short straddle portfolios for these two groups of stocks. We report the results of these computations for straddle portfolios in Panel A of Table 8.

\footnotetext{
${ }^{21}$ We thank Tarun Chordia for making these data available to us.
} 
Portfolio returns decrease substantially, as expected, after taking transaction costs into account. The long-short straddle portfolio returns are reduced from $22.5 \%$ to $7.5 \%$ per month if we consider trading options at an effective spread equal to the quoted spread. The liquidity of options also has an impact on returns as returns are higher for thinly traded stocks. Consider, as an illustration, the results obtained by sorting on the average bid-ask spread of options. The returns, computed from mid-points, to the long-short straddle portfolio are $18.2 \%$ for stocks with more liquid options (low bid-ask spreads) and $27.7 \%$ for stocks with less liquid options (high bid-ask spreads). These returns decline further with transaction costs. If effective spreads are the same as quoted spreads, the returns are still significantly positive at $9.4 \%$ for more liquid options and $5.9 \%$, but insignificant, for less liquid options. This pattern arises because, by construction, the impact of transaction costs (as measured by spreads) is higher for stocks with less liquid options. The results are qualitatively the same when we sort stocks based on the options average daily trading volume.

The cost-adjusted performance of delta-hedged portfolios is investigated in detail in Panel B of Table 8. The pattern of higher returns for more illiquid options found in Panel A is repeated Panel B. For instance, the returns (calculated using midpoints) on deltahedged calls increase from $2.1 \%$ to $3.4 \%$ per month, and the returns on delta-hedged puts increase from $2.3 \%$ to $2.9 \%$ per month, as one goes from the less liquid stock options to the more liquid stock options (liquidity as measured by bid-ask spreads). Spreads decrease these returns on the portfolios. For effective spreads equal to the quoted spreads, the delta-hedged calls (puts) have statistically insignificant returns of around $0.6 \%(0.6 \%)$.

Santa-Clara and Saretto (2005) show that margin requirements on written option positions can be quite effective at preventing investors to take advantage of large profit opportunities in the S\&P 500 options market. However, margins on short positions have a smaller impact on trades that involve options with strike prices close to at-the-money. The short side of the long-short strategy involves options with high current IV. Therefore, these options have high prices and relatively high price-to-underlying ratios. Margin requirements for these options are relatively low and do not materially affect the execution of our strategies.

We conclude that trading costs reduce the profits to our portfolios but do not eliminate them at reasonable estimates of effective spreads. ${ }^{22}$ We also find that the profitability of

\footnotetext{
${ }^{22}$ Please note that we skip an additional day in constructing our portfolio strategies. While our motivation for this procedure is to avoid microstructure issues, the unintended consequence of this approach is that our traders trade only based on the closing quotes on Tuesday. In actual practice, the option
} 
option portfolios is higher for less liquid options.

\section{Discussion}

\subsection{Temporary or persistent deviations?}

In this section, we explore whether these deviations of IV from $\mathrm{HV}$ are temporary, as we conjectured earlier in the paper, and what are the determinants of these deviations. We first analyze the pattern of volatilities before and after portfolio formation month. We plot the level of IV and the difference of HV and IV twelve months before and after portfolio formation date for the extreme deciles in Figure 2. By construction, decile one (ten) consists of stocks with large negative (positive) differences between HV and IV at time 0 . We also see that IV in decile one (ten) is higher (lower) than its own twelve-month moving average. The figure also shows a striking pattern of IV after portfolio formation. IV for decile one (ten) decreases (increases) after portfolio formation almost as quickly as it increases (decreases) in the months preceding the portfolio formation date. The pattern of changes in IV is not accompanied by similar pattern of changes in $\mathrm{HV}$ - the deviations of $\mathrm{HV}$ and IV are the highest at time 0 (by construction) and are insignificant a year before and after portfolio formation. These results show that deviations of HV from IV are indeed not persistent.

What leads to these temporary deviations? Stocks in decile one (ten) have returns of $-1.9 \%(3.7 \%)$ in the month immediately preceding the portfolio formation date. Investors, cognizant of the asymmetric volatility (Black (1976)) effect, will revise upwards (downwards) their estimates of future volatility for stocks in decile one (ten). This will lead to an increase (decrease) in IV for options in decile one (ten), consistent with the data that we observe. In unreported results, we find that these expectations of changes in future volatility are partly justified - the realized volatility in the month subsequent to portfolio formation does increase (decrease) for decile one (ten). Therefore, the current IV predicts future realized volatility. However, we also find that the changes in future realized volatility are smaller in magnitude than what implied by the spikes in IV at portfolio formation. This fact suggests that investors over-react to current events (stock returns) in their estimation of future volatility at portfolio formation. Our findings mirror

traders would have the whole day to decide when to optimally trade and minimize the market impact costs. 
those of Stein (1989). Stein studies the term structure of the implied volatility of index options and finds that investors ignore the long-run mean reversion in implied volatility and instead overweight the current short-term implied volatility in their estimates of long-term implied volatility. Our findings are also consistent with those of Poteshman (2001), who finds that investors in the options market over-react, particularly to periods of increasing or decreasing changes in volatility. This is analogous to our deciles one and ten, which exhibit the greatest changes in volatility, and are also characterized by the most mispricing.

\subsection{Alternative estimate of implied volatility}

Can one use the information in the cross-section of volatilities to under-weigh idiosyncratic events (individual stock returns) and form better expectations about future individual volatility? We test this conjecture by forming alternative real-time estimates of implied volatility using cross-sectional regressions. We want to use these alternative measures to recalculate option prices and check whether these repriced options lead to excess returns.

As a first step in this exercise, we estimate a cross-sectional regression model for implied volatility, similar in spirit to that of Jegadeesh (1990) who identifies predictable patterns in the cross-section of stock returns. Each month $t$, we specify the model as follows:

$$
\Delta i v_{i, t}=\alpha_{t}+\beta_{1 t} i v_{i, t-1}+\beta_{2 t}\left(i v_{i, t-1}-\overline{i v}_{i, t-13: t-2}\right)+\beta_{3 t}\left(i v_{i, t-1}-h v_{i, t-12: t-1}\right)+\epsilon_{i, t}
$$

where $i v_{i, t}$ is the natural logarithm of the ATM IV for stock $i$ measured at month $t$, $\overline{i v}_{i, t-13: t-2}$ is the natural logarithm of the twelve months moving average of $\operatorname{IV}_{i}, h v_{i, t-12: t-1}$ is the natural logarithm of the historical realized volatility (calculated using months $t-12$ to $t-1$ ) for stock $i$. Our model is motivated by the existing empirical evidence of a high degree of mean-reversion in realized volatility, and by the evidence presented in the previous subsections. In addition to the volatility signal (log difference between $\mathrm{HV}$ and IV) we include the log level of implied volatility as well as the log difference between the level of implied volatility and its twelve months moving average. We predict the log change in implied volatility, instead of the level, to avoid the possibility of predicting a negative level. We estimate a Fama and MacBeth (1973) regression wherein each crosssectional estimate is computed on the Monday following the third Friday of the month. We tabulate averages of the cross-sectional estimates and $t$-statistics adjusted for serial 
correlation in Panel A of Table 9. We also report the in-sample fit of these regressions measured by the average $\bar{R}_{t}^{2}$ of each monthly cross-sectional regression. We find that the change in IV is negatively related to the last period IV, the difference between last period IV and its twelve-month moving average, and the difference between IV and HV. The average $\bar{R}^{2}$ is quite large at $21 \%$, and at times it is as high as $50 \%$.

Second, we compute a prediction of each stock's implied volatility in a real time fashion:

$$
\Delta \widehat{i v}_{i, t}=\widehat{\alpha}_{t}+\widehat{\beta}_{1 t} i v_{i, t}+\widehat{\beta}_{2 t}\left(i v_{i, t}-\overline{i v}_{i, t-12: t-1}\right)+\widehat{\beta}_{3 t}\left(i v_{i, t}-h v_{i, t-11: t}\right) .
$$

The above equation is a direct analog of equation (11) except that we use the current month's variables on the right hand side of equation (12) in order to use the most recent information for our prediction: we use IV and HV measures available at $t$ and parameter estimates also obtained at time $t$. We obtain the prediction of the implied volatility level $\left(\widehat{\mathrm{IV}}_{i, t}\right)$ in the following way:

$$
\widehat{\mathrm{IV}}_{i, t}=\mathrm{IV}_{i, t} \times e^{\Delta \widehat{i v}_{i, t}}
$$

Panel B of Table 9 gives descriptive statistics on portfolios sorted on the difference between HV and IV (the same sorting criterion as in the rest of the paper). We find that $\widehat{\mathrm{IV}}$ is higher (lower) than IV for decile ten (one). The economic implication of this alternative estimate of implied volatility is then pursued by repricing the options involved in the portfolio strategies by plugging the $\widehat{\mathrm{IV}}$ estimate into the Black-Scholes model. The returns (computed using the 'recalculated' prices) on long-short portfolios of delta-hedged calls/puts and straddles, while preserving the original sorting, are both economically and statistically insignificant.

Please note that, since the options are American and volatility is stochastic, the BlackScholes formula is obviously incorrect for pricing. However, our objective in this exercise is not to compute the 'true' price of the option, rather it is to show that, on average, superior returns to portfolios are related only to volatility (option price) mis-estimation. These results are consistent with our earlier hypothesis that there is valuable information contained in the cross-section of implied volatilities which is disregarded by option traders.

\subsection{Risk-neutral or physical measure}

Our evidence shows that expensive options with high IV (relative to HV) earn low returns and cheap options with low IV (relative to HV) earn high returns. We acknowledge the 
existence of stochastic volatility and do not claim that IV has to be very close to $\mathrm{HV}$. In fact, there are strong theoretical reasons to believe that IV may not even be close to future realized volatility. IV is only the expectation of future volatility under the risk-neutral measure. A non-zero price of volatility risk will, therefore, drive a wedge between IV and volatility (either historical or future). ${ }^{23}$ In particular, stocks with negative (positive) price of volatility risk will have IV higher (lower) than HV. We show in equation (4) that the return on an option is directly related to its price of volatility risk $\left(\lambda_{2}^{i}\right)$, which ultimately depends upon the aggregate prices of risk and the stock sensitivities to the aggregate risk factors. Therefore, as it is the case for stocks, low (high) sensitivities to the aggregate risk factors are associated with low (high) expected option returns. To summarize, crosssectional variation in the stock prices of volatility risk will lead to cross-sectional variation in the deviation of IV from HV with positive deviation (such as that in decile one) being associated with low expected option returns and negative deviation (such as that in decile ten) being associated with high expected option returns.

While the above story is qualitatively consistent with the patterns in the observed data, we can rule out this explanation of our results for three reasons. First, the price of volatility risk should be quite large to generate the large deviations of HV from IV that we observe in the data. ${ }^{24}$ Second, since the deviations of HV from IV are not persistent the time variation in the stock prices of risk (i.e. the stock sensitivities to the aggregate factors, $\lambda_{2}^{i}$ 's) would have to be quite dramatic because our portfolios do not exhibit large difference between $\mathrm{HV}$ and IV soon before/after portfolio formation. Third, and most important, equation (6) shows that, given aggregate prices of volatility risk, the option returns will be explained by their loadings on market-wide risk factors. However, we find in Sections 4.1 and 4.2 that these loadings, in particular the loadings on the aggregate volatility factor reported in Table 5, fail to capture the systematic variation in option returns. We conclude that the existence of a price of volatility risk does not explain our results.

\footnotetext{
${ }^{23}$ Whether or not there is a price of volatility risk for individual stocks is a topic of active current research. See Driessen, Maenhout, and Vilkov (2006) for one perspective on this issue.

${ }^{24} \mathrm{~A}$ simple calibration of a Heston (1993) stochastic volatility model with a volatility risk premium of $15 \%$ per month generates a difference between implied and realized volatility of $2-3 \%$ depending on model parameters, therefore matching the empirically observed data on the aggregate volatility (Coval and Shumway (2001)). The deviations of IV from HV for individual stocks in deciles one/ten in Table 2 are almost one order of magnitude larger than those for aggregate volatility (even after acknowledging the fact that the volatility process of individual stocks exhibit a larger volatility of volatility and a faster degree of mean-reversion).
} 


\section{Conclusion}

We emphasize that our results do not depend on the validity of the Black and Scholes (1973) or the Cox, Ross, and Rubinstein (1979) model. Implied volatilities should be interpreted as representation of option prices. Therefore the reader should view our portfolio sorts as sorts on option prices with decile one (ten) representing cheap (expensive) options. This perspective does not require one to take a stand on the correct option pricing model. The objective of our paper is to document the existence of a substantial spread in the cross-section of U.S. equity options sorted on a very simple criterion.

The underlying reason for the empirical regularity that we observe in equity option prices is unclear. While we find that our option returns are not related to obvious sources of risk, we can not conclusively establish that these are true 'alphas.' It is possible that the profits to our volatility portfolios arise as compensation for some unknown aggregate risk. If such is indeed the case, the daunting task of formulating a cross-sectional options return model that accounts for our portfolios returns is left to future research.

If, instead, these returns are abnormal, the evidence presented in the paper raises the question of what accounts for this volatility mispricing. It may be that economic agents do not use all the available information in forming expectations about future stock volatilities. In particular, they ignore the information contained in the cross-sectional distribution of implied volatilities and consider assets individually when forecasting volatility. This leads them to mis-estimate the mean reversion parameter in the underlying stochastic volatility and, therefore, incorrectly price the option. The fact that the alternative implied volatility estimates computed from our cross-sectional model eliminate the portfolio profitability lends some credence to this possibility. Although it is not clear whether the failure to incorporate cross-sectional information in volatility forecasts reflects behavioral biases, our evidence is also broadly consistent with the possibility that the investors overreact to current information. 


\section{References}

Andersen, Torben G., Tim Bollerslev, Peter F. Christoffersen, and Francis X. Diebold, 2006, Volatility and Correlation Forecasting, in Elliott Graham, Clive W.J. Granger, and Allan Timmermann, eds.: Handbook of Economic Forecasting (North-Holland, Amsterdam ).

Bakshi, Gurdip, and Nikunj Kapadia, 2003, Delta-hedged gains and the negative market volatility risk premium, Review of Financial Studies 16, 527-566.

Battalio, Robert, Brian Hatch, and Robert Jennings, 2004, Toward a national market system for U.S. exchange-listed equity options, Journal of Finance 59, 933-962.

Battalio, Robert, and Paul Schultz, 2006, Options and the bubble, Journal of Finance 61, 2071-2102.

Black, Fischer, 1976, Studies of stock price volatility changes, Proceeding of the 1976 meetings of the 1025 American Statistical Association, Business and Economical Statistics Section pp. 177-181.

Black, Fischer, and Myron Scholes, 1973, The pricing of options and corporate liabilities, Journal of Political Economy 81, 637-654.

Brennan, Michael J., Tarun Chordia, and Avanidhar Subrahmanyam, 1998, Alternative factor specifications, security charachteristics, and the cross-section of expected returns, Journal of Financial Economics 49, 345-373.

Britten-Jones, Mark, and Anthony Neuberger, 2000, Option prices, implied price processes, and stochastic volatility, Journal of Finance 55, 839-866.

Carhart, Mark M., 1997, On persistence in mutual fund perfromance, Journal of Finance $52,57-82$.

Chava, Sudheer, and Heather Tookes, 2006, Where (and How) Does News Impact Trading?, Working paper.

Cochrane, John H., 2001, Asset Pricing. (Princeton University Press Princeton, New Jersey).

Coval, Joshua D., and Tyler Shumway, 2001, Expected option returns, Journal of Finance 56, 983-1009.

Cox, John, Stephen Ross, and Mark Rubinstein, 1979, Option pricing: A simplified approach, Journal of Financial Economics 7, 229-263.

De Fontnouvelle, Patrick, Raymond P.H. Fisher, and Jeffrey H. Harris, 2003, The behavior of bid-ask spreads and volume in options markets during the competition for listings in 1999, Journal of Finance 58, 2437-2463. 
Diether, Karl B., Christopher J. Malloy, and Anna Scherbina, 2002, Differences of opinion and the cross-section of stock returns, Journal of Finance 56, 2113-2141.

Driessen, Joost, Pascal Maenhout, and Gregory Vilkov, 2006, Option-implied correlations and the price of correlation risk, Working paper.

Duan, Jin-Chuan, and Jason Wei, 2007, Systematic risk and the price structure of individual equity options, Working paper, forthcoming in Review of Financial Studies.

Duarte, Jefferson, and Christopher S. Jones, 2007, The price of market volatility risk, Working paper.

Dubinsky, Andrew, and Michael Johannes, 2005, Earnings announcements and equity options, Working paper.

Easley, David, Maureen O'Hara, and P.S. Srinivas, 1998, Option volume and stock prices: evidence on where informed traders trade, Journal of Finance 53, 431-465.

Fama, Eugene F., and Kenneth R. French, 1993, Common risk factors in the returns on stocks and bonds, Journal of Financial Economics 33, 3-56.

Fama, Eugene F., and James D. MacBeth, 1973, Risk, return, and equilibrium: empirical tests, Journal of Political Economy 81, 607-636.

Figlewski, Stephen, 1989, Options arbitrage in imperfect markets, Journal of Finance 44, 1289-1311.

Friend, Irwin, and Randolph Westerfield, 1980, Co-skewness and capital asset pricing, Journal of Finance 35, 897-913.

George, Thomas J., and Francis A. Longstaff, 1993, Bid-ask spreads and trading activity in the S\&P 100 index option market, Journal of Financial and Quantitative Analysis $28,381-397$.

Gould, John P., and Dan Galai, 1974, Transactions costs and the relationship between put and call prices, Journal of Financial Economics 1, 105-129.

Granger, Clive W.J., and Ser-Huang Poon, 2003, Forecasting volatility in financial markets: a review, Journal of Economic Literature 41, 478-539.

Green, Clifton T., and Stephen Figlewski, 1999, Market risk and model risk for financial institution writing options, Journal of Finance 54, 1465-1499.

Hanna, J. Douglas, and Mark J. Ready, 2005, Profitable predictability in the cross section of stock returns, Journal of Financial Economics 78, 463-505.

Harvey, Campbell R., and Akhtar Siddique, 2000, Conditional skewness in asset pricing tests, Journal of Finance 55, 1263-1295. 
Heston, Steven, 1993, A closed form solution for options with stochastic volatility with applications to bond and currency options, Review of Financial Studies 6, 327-343.

Ho, Thomas S.Y., and Richard G. Macris, 1984, Dealer bid-ask quotes and transaction prices: an empirical study of some AMEX options, Journal of Finance 39, 23-45.

Jegadeesh, Narasimhan, 1990, Evidence of predictable behavior of security returns, Journal of Finance 45, 881-898.

Jiang, George J., and Yisong S. Tian, 2005, The model-free implied volatility and its information content, Review of Financial Studies 18, 1305-1342.

Kraus, Alan, and Robert H. Litzenberger, 1976, Skewness preference and the valuation of risky assets, Journal of Finance 31, 1085-1100.

Leland, Hayne E., 1999, Beyond mean-variance: performance measurement in a nonsymmetrical world, Financial Analysts Journal 55, 27-36.

Mayhew, Stewart, 2002, Competition, market structure, and bid-ask spreads in stock option markets, Journal of Finance 57, 931-958.

Ni, Sophie Xiaoyan, 2006, Stock option return: a puzzle, Working Paper.

Ni, Sophie Xiaoyan, Jun Pan, and Allen M. Poteshman, 2006, Volatility Information Trading in the Option Market, Working Paper.

Ofek, Eli, Matthew Richardson, and Robert F. Whitelaw, 2004, Limited arbitrage and short sales restrictions: evidence from the options market, Journal of Financial Economics 74, 305-342.

Pan, Jun, and Allen M. Poteshman, 2006, The information in option volume for future stock prices, Review of Financial Studies 19, 871-908.

Pástor, Lǔboš, and Robert F. Stambaugh, 2003, Liquidity risk and expected stock returns, Journal of Political Economy 111, 642-685.

Poteshman, Allen M., 2001, Underreaction, overreaction, and increasing misreaction to information in the options market, Journal of Finance 56, 851-876.

Poteshman, Allen M., and Vitaly Serbin, 2003, Clearly irrational financial market behavior: Evidence from the early exercise of exchange traded stock options, Journal of Finance 58, 37-70.

Sadka, Ronnie, 2006, Momentum and post-earnings-announcement drift anomalies: The role of liquidity risk, Journal of Financial Economics 80, 309-349.

Santa-Clara, Pedro, and Alessio Saretto, 2005, Option strategies: Good deals and margin calls, UCLA working paper. 
Stein, Jeremy, 1989, Overreactions in the options market, Journal of Finance 44, 10111023.

Swidler, Steve, and David J. Diltz, 1992, Implied volatilities and transaction costs, Journal of Financial and Quantitative Analysis 27, 437-447. 


\section{Figure 1: VIX and IV}

We select one call and one put for each stock in each month of the sample period. All options have expirations of one month and moneyness close to one. The IV for each stock is the average of the IV of the selected call and put. All options are American. The figure plots the time-series of VIX and the time-series of the average IV. The sample period is January 1996 to December 2005.

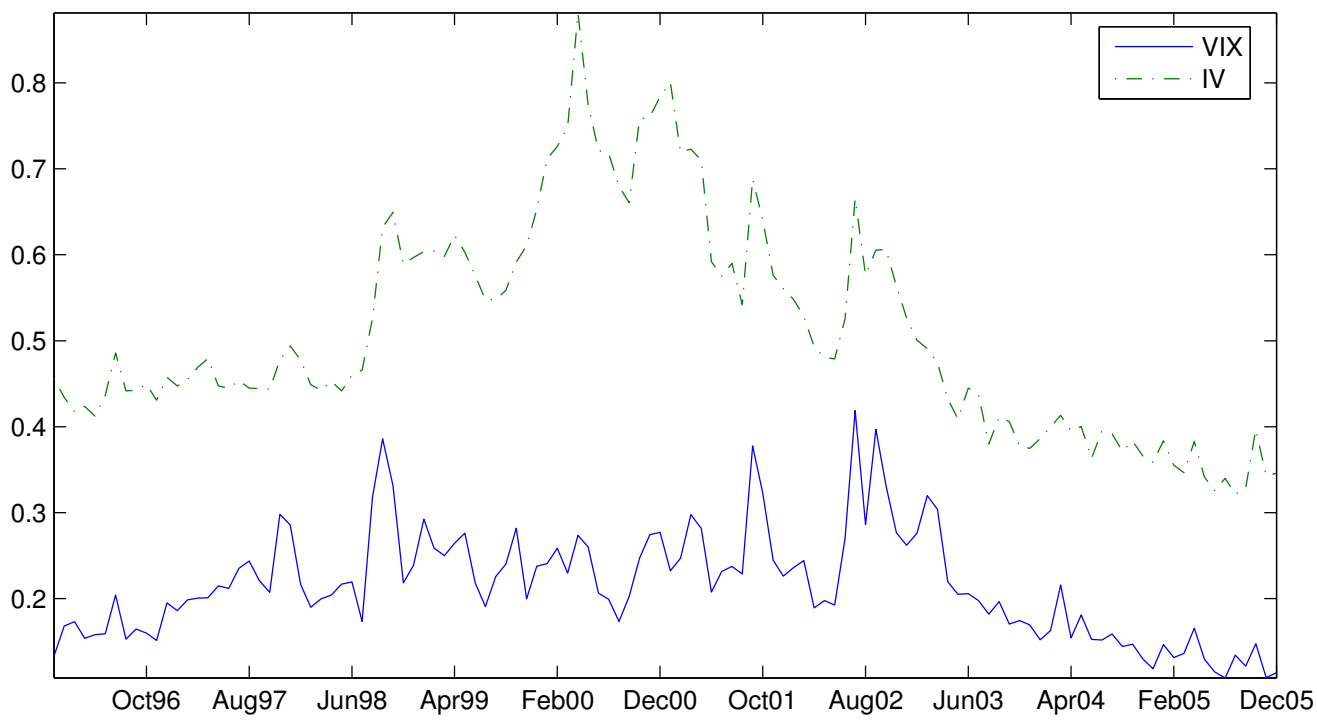


Figure 2: Volatilities Before and After Portfolio Formation

Portfolios are formed as in Table 2. We plot the IV (in Panel A) and the difference in HV and IV (in Panel B) for a period of twelve months before to twelve months after portfolio formation.

Panel A: IV

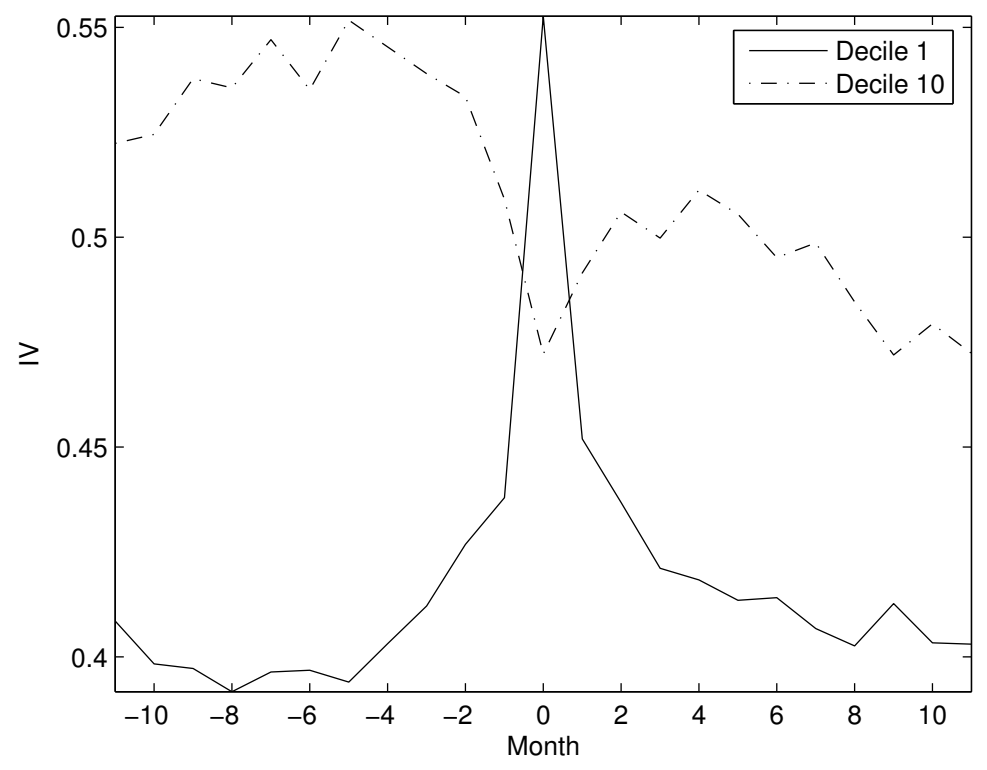

Panel B: HV-IV

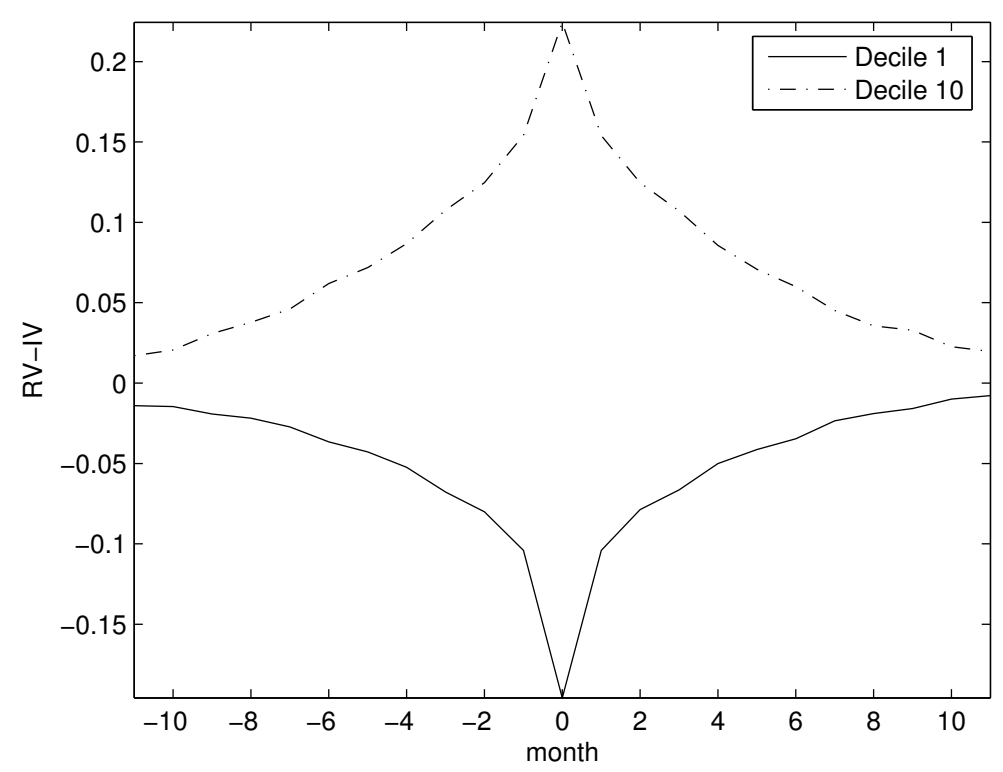




\section{Table 1: Summary Statistics}

We select one call and one put for each stock in each month of the sample period. All options have expirations of one month and moneyness close to one. We first compute the time-series average of these volatilities for each stock and then report the cross-sectional average of these average volatilities. The other statistics are computed in a similar fashion. Historical volatility $(\mathrm{HV})$ is calculated using the standard deviation of daily realized stock returns over the most recent twelve months. Implied volatility (IV) for each stock is the average of the selected call and put. The volatilities are in annualized basis. The sample period is 1996 to 2005 .

\begin{tabular}{lccccccc}
\hline & Mean & Median & StDev & Min & Max & Skew & Kurt \\
\hline IV & 0.584 & 0.569 & 0.113 & 0.454 & 0.775 & 0.424 & 2.391 \\
HV & 0.604 & 0.599 & 0.096 & 0.488 & 0.744 & 0.179 & 2.046 \\
& & & & & & & \\
$\Delta$ IV & -0.009 & -0.011 & 0.131 & -0.189 & 0.181 & 0.075 & 2.207 \\
$\Delta$ HV & -0.001 & -0.001 & 0.016 & -0.025 & 0.022 & -0.023 & 2.963 \\
\hline
\end{tabular}




\section{Table 2: Formation-Period Statistics of Portfolios Sorted on the Difference Between HV and IV}

We sort stocks into deciles based on the difference between the HV and the IV. All statistics are first averaged across stocks in each decile and then averaged across time. $\omega$ is the volatility of volatility calculated using standard deviation of daily implied volatilities during the six last months and $\rho$ is the correlation between daily changes in implied volatility and stock returns calculated using the last six months. $\Delta, \Gamma$, and $\mathcal{V}$ are the delta, gamma, and vega, respectively, of the options. The sample period is 1996 to 2005.

\begin{tabular}{lrrrrrrrrrr}
\hline Decile & 1 & 2 & 3 & 4 & 5 & 6 & 7 & 8 & 9 & 10 \\
\hline & & & & & & & & & & \\
$\mathrm{HV}_{t}-\mathrm{IV}_{t}$ & -0.165 & -0.074 & -0.041 & -0.017 & 0.004 & 0.024 & 0.046 & 0.071 & 0.110 & 0.226 \\
$\mathrm{HV}_{t}$ & 0.438 & 0.454 & 0.453 & 0.467 & 0.480 & 0.501 & 0.527 & 0.551 & 0.596 & 0.731 \\
$\mathrm{IV}_{t}$ & 0.602 & 0.527 & 0.495 & 0.484 & 0.476 & 0.476 & 0.481 & 0.479 & 0.486 & 0.504 \\
& & & & & & & & & & \\
$\omega$ & 0.029 & 0.024 & 0.023 & 0.023 & 0.023 & 0.024 & 0.025 & 0.026 & 0.028 & 0.035 \\
$\rho(\sigma, r)$ & -0.287 & -0.330 & -0.350 & -0.367 & -0.364 & -0.367 & -0.364 & -0.369 & -0.362 & -0.319 \\
& & & & & & & & & & \\
$\Delta^{c}$ & 0.547 & 0.541 & 0.543 & 0.541 & 0.539 & 0.534 & 0.531 & 0.529 & 0.535 & 0.530 \\
$\Delta^{p}$ & -0.456 & -0.464 & -0.461 & -0.463 & -0.466 & -0.472 & -0.475 & -0.475 & -0.471 & -0.476 \\
$\Gamma$ & 0.102 & 0.102 & 0.104 & 0.104 & 0.108 & 0.108 & 0.112 & 0.114 & 0.119 & 0.137 \\
$\mathcal{V}$ & 4.337 & 4.768 & 4.915 & 4.862 & 4.781 & 4.855 & 4.586 & 4.670 & 4.543 & 4.174 \\
$(\mathrm{C} / \mathrm{S})$ & 0.066 & 0.058 & 0.055 & 0.055 & 0.053 & 0.053 & 0.053 & 0.053 & 0.055 & 0.056 \\
$(\mathrm{P} / \mathrm{S})$ & 0.063 & 0.056 & 0.052 & 0.051 & 0.051 & 0.052 & 0.052 & 0.053 & 0.053 & 0.056 \\
\hline
\end{tabular}




\section{Table 3: Post-Formation Returns of Portfolios Sorted on the Difference Between HV and IV}

Portfolios are formed as in Table 2. The returns on options are constructed using, as a reference beginning price, the average of the closing bid and ask quotes and, as the closing price, the terminal payoff of the option depending on the stock price and the strike price of the option. The hedge ratio for the delta-hedged portfolios is calculated using the current IV estimate. The options monthly returns are averaged across all the stocks in the volatility decile. SR is the Sharpe ratio and $\mathrm{CE}$ is the certainty equivalent. CE is computed from a utility function with constant relative risk-aversion parameters of three and seven. The sample period is 1996 to 2005.

\begin{tabular}{|c|c|c|c|c|c|c|c|c|c|c|c|}
\hline Decile & 1 & 2 & 3 & 4 & 5 & 6 & 7 & 8 & 9 & 10 & $10-1$ \\
\hline \multicolumn{12}{|c|}{ Panel A: Straddle Returns } \\
\hline mean & -0.099 & -0.065 & -0.041 & -0.010 & -0.001 & 0.004 & 0.011 & -0.006 & 0.045 & 0.126 & 0.225 \\
\hline std & 0.198 & 0.217 & 0.263 & 0.259 & 0.272 & 0.277 & 0.253 & 0.262 & 0.303 & 0.335 & 0.314 \\
\hline $\min$ & -0.489 & -0.466 & -0.554 & -0.480 & -0.473 & -0.526 & -0.575 & -0.383 & -0.497 & -0.422 & -0.405 \\
\hline $\max$ & 0.598 & 0.669 & 1.257 & 1.087 & 1.485 & 1.317 & 0.924 & 1.026 & 1.578 & 1.766 & 1.440 \\
\hline $\mathrm{SR}$ & -0.514 & -0.313 & -0.168 & -0.052 & -0.015 & 0.002 & 0.032 & -0.034 & 0.139 & 0.367 & 0.718 \\
\hline $\mathrm{CE}(\gamma=3)$ & -0.160 & -0.136 & -0.140 & -0.091 & -0.082 & -0.089 & -0.081 & -0.085 & -0.051 & 0.016 & 0.111 \\
\hline $\mathrm{CE}(\gamma=7)$ & -0.232 & -0.217 & -0.258 & -0.177 & -0.163 & -0.207 & -0.223 & -0.157 & -0.154 & -0.091 & -0.038 \\
\hline
\end{tabular}

Panel B: Delta-Hedged Call Returns

\begin{tabular}{lrrrrrrrrrrr}
\hline & & & & & & & & & & & \\
mean & -0.015 & -0.009 & -0.008 & -0.005 & -0.003 & -0.001 & 0.000 & -0.001 & 0.006 & 0.012 & 0.027 \\
std & 0.031 & 0.030 & 0.032 & 0.028 & 0.030 & 0.035 & 0.033 & 0.034 & 0.040 & 0.043 & 0.044 \\
$\min$ & -0.111 & -0.087 & -0.090 & -0.089 & -0.070 & -0.089 & -0.061 & -0.060 & -0.087 & -0.068 & -0.074 \\
$\max$ & 0.068 & 0.101 & 0.122 & 0.129 & 0.135 & 0.162 & 0.140 & 0.138 & 0.207 & 0.189 & 0.209 \\
SR & -0.580 & -0.415 & -0.333 & -0.283 & -0.201 & -0.113 & -0.087 & -0.107 & 0.066 & 0.216 & 0.612 \\
$\mathrm{CE}(\gamma=3)$ & -0.016 & -0.011 & -0.009 & -0.006 & -0.004 & -0.003 & -0.001 & -0.002 & 0.003 & 0.010 & 0.024 \\
$\mathrm{CE}(\gamma=7)$ & -0.018 & -0.012 & -0.011 & -0.008 & -0.006 & -0.005 & -0.003 & -0.004 & 0.001 & 0.007 & 0.021 \\
\hline
\end{tabular}

Panel C: Delta-Hedged Put Returns

\begin{tabular}{lrrrrrrrrrrr}
\hline & & & & & & & & & & & \\
mean & -0.012 & -0.007 & -0.004 & -0.002 & -0.001 & 0.001 & 0.002 & -0.000 & 0.005 & 0.013 & 0.026 \\
std & 0.025 & 0.024 & 0.030 & 0.025 & 0.025 & 0.029 & 0.028 & 0.028 & 0.034 & 0.037 & 0.038 \\
$\min$ & -0.080 & -0.074 & -0.102 & -0.077 & -0.060 & -0.121 & -0.062 & -0.058 & -0.069 & -0.044 & -0.057 \\
$\max$ & 0.061 & 0.061 & 0.114 & 0.100 & 0.100 & 0.136 & 0.110 & 0.121 & 0.213 & 0.190 & 0.199 \\
SR & -0.615 & -0.428 & -0.252 & -0.197 & -0.160 & -0.069 & -0.035 & -0.120 & 0.070 & 0.274 & 0.676 \\
CE $(\gamma=3)$ & -0.013 & -0.008 & -0.006 & -0.003 & -0.002 & -0.000 & 0.001 & -0.001 & 0.004 & 0.011 & 0.024 \\
CE $(\gamma=7)$ & -0.015 & -0.009 & -0.007 & -0.004 & -0.003 & -0.002 & -0.001 & -0.003 & 0.002 & 0.009 & 0.021 \\
\hline
\end{tabular}




\section{Table 4: Expected Option Returns}

The individual stock returns follow a one-factor model and the market return has stochastic volatility. Both stock-risk and volatility risk are priced. Further details are in the text. The expected return on a delta-hedged option in this model is given by:

$$
E\left(\frac{d H_{t}^{i}}{H_{t}^{i}}\right)-r_{t} d t=\frac{1}{f_{i}} \frac{\partial f_{i}}{\partial \sigma_{t}^{i}}\left(\beta_{m t}^{i} \sigma_{t}^{m} \lambda_{1 t}^{m}+\beta_{\sigma t}^{i} \omega_{t}^{m} \sqrt{1-\rho^{m 2}} \lambda_{2 t}^{m}\right) d t
$$

where $\lambda^{\prime} s$ are prices of risk, $\rho$ is the correlation between the Brownian motions for return and volatility processes, $\omega$ is the volatility of volatility. The betas, $\beta_{m}^{i}$ and $\beta_{\sigma}^{i}$, are estimated from regressions of scaled delta-hedged option returns on the market portfolio return and scaled deltahedged market portfolio return, respectively. The market parameters used are: $\lambda_{1}^{m}=0.16$, $\lambda_{2}^{m}=-0.12, \sigma^{m}=0.06, \omega^{m}=0.05 / \sqrt{12}$, and $\rho^{m}=-0.7$. The row titled $E\left[H_{i}\right]$ gives the expected return based on above equation (the expected return in the table is adjusted for the variance term). The row titled $\overline{H_{i}}$ is the actual return and $\alpha$ is the difference between the actual and the expected return. Actual returns on portfolios are the same as those in Table 3. The sample period is 1996 to 2005 .

\begin{tabular}{|c|c|c|c|c|c|c|c|c|c|c|c|}
\hline Decile & 1 & 2 & 3 & 4 & 5 & 6 & 7 & 8 & 9 & 10 & $10-1$ \\
\hline \multicolumn{12}{|c|}{ Panel A: Delta-Hedge Call Returns } \\
\hline$\beta_{m k t}^{c}$ & -0.055 & 0.003 & -0.041 & -0.059 & -0.027 & -0.015 & 0.012 & -0.112 & 0.005 & 0.019 & 0.074 \\
\hline$\beta_{v i x}^{c}$ & 0.252 & 0.316 & 0.306 & 0.317 & 0.288 & 0.306 & 0.277 & 0.277 & 0.281 & 0.215 & -0.037 \\
\hline$E\left[H^{c}\right]$ & -0.000 & -0.003 & -0.002 & -0.003 & 0.000 & -0.001 & -0.002 & -0.005 & 0.000 & 0.002 & 0.002 \\
\hline$\overline{H^{c}}$ & -0.015 & -0.009 & -0.008 & -0.005 & -0.003 & -0.001 & 0.000 & -0.001 & 0.006 & 0.012 & 0.027 \\
\hline$\alpha$ & -0.013 & -0.006 & -0.006 & -0.002 & -0.003 & 0.000 & 0.001 & 0.005 & 0.005 & 0.011 & 0.025 \\
\hline \multicolumn{12}{|c|}{ Panel B: Delta-Hedge Put Returns } \\
\hline$\beta_{m k t}^{p}$ & -0.047 & 0.016 & -0.054 & -0.004 & -0.048 & 0.004 & -0.015 & 0.028 & 0.021 & 0.065 & 0.112 \\
\hline$\beta_{v i x}^{p k i t}$ & 0.182 & 0.200 & 0.200 & 0.200 & 0.201 & 0.197 & 0.203 & 0.198 & 0.200 & 0.172 & -0.010 \\
\hline$E\left[H^{p}\right]$ & -0.001 & -0.000 & -0.002 & -0.000 & -0.001 & 0.001 & -0.001 & 0.001 & 0.001 & 0.003 & 0.003 \\
\hline$\overline{H^{p}}$ & -0.012 & -0.007 & -0.004 & -0.002 & -0.001 & 0.001 & 0.002 & -0.000 & 0.005 & 0.013 & 0.026 \\
\hline$\alpha$ & -0.011 & -0.007 & -0.002 & -0.001 & 0.001 & 0.000 & 0.003 & -0.001 & 0.004 & 0.011 & 0.022 \\
\hline
\end{tabular}




\section{Table 5: Risk-Adjusted Option Returns}

We present results from the following time-series regression of 10-1 portfolio returns:

$$
R_{p t}=\alpha_{p}+\beta_{p} F_{t}+e_{p t} .
$$

We consider risk factors from the Fama and French (1993) three-factor model (MKT-Rf, SMB, and HML), the Carhart (1997) momentum factor (MOM), and the Coval and Shumway (2001) excess zero-beta S\&P 500 straddle factor (ZBSTRAD-Rf). DHCALL and DHPUT are S\&P 500 delta-hedged call and put factor returns. The first row gives the coefficients while the second row gives the $t$-statistics in parenthesis. The sample period is 1996 to 2005 .

\begin{tabular}{|c|c|c|c|c|c|c|}
\hline & \multicolumn{2}{|c|}{ Straddles } & \multicolumn{4}{|c|}{ Delta-Hedged } \\
\hline & \multirow[b]{2}{*}{$(1)$} & \multirow[b]{2}{*}{$(2)$} & \multicolumn{2}{|c|}{ Calls } & \multicolumn{2}{|c|}{ Puts } \\
\hline & & & $(3)$ & $(4)$ & $(5)$ & $(6)$ \\
\hline Alpha & $\begin{array}{c}0.244 \\
(8.91)\end{array}$ & $\begin{array}{r}0.239 \\
(8.26)\end{array}$ & $\begin{array}{r}0.028 \\
(6.69)\end{array}$ & $\begin{array}{r}0.029 \\
(5.72)\end{array}$ & $\begin{array}{r}0.026 \\
(7.45)\end{array}$ & $\begin{array}{r}0.026 \\
(6.44)\end{array}$ \\
\hline $\mathrm{MKT}-\mathrm{Rf}$ & $\begin{array}{l}-0.365 \\
(-0.45)\end{array}$ & $\begin{array}{c}-0.397 \\
(-0.47)\end{array}$ & $\begin{array}{c}-0.040 \\
(-0.33)\end{array}$ & $\begin{array}{l}-0.039 \\
(-0.36)\end{array}$ & $\begin{array}{r}0.015 \\
(0.13)\end{array}$ & $\begin{array}{c}0.021 \\
(0.20)\end{array}$ \\
\hline SMB & & $\begin{array}{l}-0.513 \\
(-0.45)\end{array}$ & & $\begin{array}{l}-0.028 \\
(-0.14)\end{array}$ & & $\begin{array}{l}-0.071 \\
(-0.38)\end{array}$ \\
\hline HML & & $\begin{array}{l}-0.722 \\
(-0.74)\end{array}$ & & $\begin{array}{r}0.008 \\
(0.04)\end{array}$ & & $\begin{array}{l}-0.020 \\
(-0.12)\end{array}$ \\
\hline MOM & & $\begin{array}{r}0.782 \\
(1.05)\end{array}$ & & $\begin{array}{l}-0.029 \\
(-0.21)\end{array}$ & & $\begin{array}{c}0.009 \\
(0.08)\end{array}$ \\
\hline ZB-STRAD - Rf & $\begin{array}{r}0.156 \\
(3.32)\end{array}$ & $\begin{array}{r}0.142 \\
(3.42)\end{array}$ & & & & \\
\hline DH-CALL - Rf & & & $\begin{array}{r}0.154 \\
(0.96)\end{array}$ & $\begin{array}{r}0.161 \\
(1.14)\end{array}$ & & \\
\hline DH-PUT - Rf & & & & & $\begin{array}{r}0.200 \\
(1.31)\end{array}$ & $\begin{array}{c}0.189 \\
(1.47)\end{array}$ \\
\hline $\bar{R}^{2}$ & 0.114 & 0.112 & -0.001 & -0.027 & 0.011 & -0.012 \\
\hline
\end{tabular}




\section{Table 6: Option Returns Controlling for Stock Characteristics (Fama-Macbeth Regressions)}

We estimate the following cross-sectional Fama-Macbeth regression for individual option returns:

$$
R_{i t}-\widehat{\beta}_{i}^{\prime} F_{i t}=\gamma_{0 t}+\gamma_{1 t}^{\prime} Z_{i t-1}+e_{i t},
$$

where the $\widehat{\beta}$ 's are calculated using a first-pass regression using the entire sample, $F$ 's are the factors, and $Z$ 's are characteristics. The factors used in risk-adjustment are the Fama and French (1993) factors, momentum factor, and an option factor. The option factors are ZBSTRAD-Rf, DHCALL, and DHPUT for straddles, delta-hedged calls, and delta-hedged puts, respectively. The characteristics are $h v-i v$ (log difference of HV and IV), Size (market capitalization), BtoM (book-to-market), Mom (last six-month cumulative stock return), and skewness and kurtosis of stock returns (calculated using the last year's daily data). The table reports the averages of $\gamma$ coefficients and the associated $t$-statistic. The last row gives the average $\bar{R}^{2}$ from the monthly regressions. The sample period is 1996 to 2005.

\begin{tabular}{|c|c|c|c|c|c|}
\hline & \multicolumn{3}{|c|}{ Straddles } & \multicolumn{2}{|c|}{ Delta-Hedged } \\
\hline & (1) & $(2)$ & (3) & $\frac{\text { Calls }}{(4)}$ & $\frac{\text { Puts }}{(5)}$ \\
\hline const & $\begin{array}{c}0.001 \\
(0.10)\end{array}$ & $\begin{array}{r}0.189 \\
(2.51)\end{array}$ & $\begin{array}{r}0.165 \\
(1.72)\end{array}$ & $\begin{array}{r}0.015 \\
(1.72)\end{array}$ & $\begin{array}{r}0.015 \\
(1.93)\end{array}$ \\
\hline$h v-i v$ & $\begin{array}{r}0.191 \\
(5.59)\end{array}$ & $\begin{array}{r}0.188 \\
(5.02)\end{array}$ & $\begin{array}{r}0.200 \\
(5.56)\end{array}$ & $\begin{array}{c}0.019 \\
(3.60)\end{array}$ & $\begin{array}{r}0.019 \\
(4.65)\end{array}$ \\
\hline Size & & $\begin{array}{l}-0.013 \\
(-2.74)\end{array}$ & $\begin{array}{l}-0.012 \\
(-2.10)\end{array}$ & $\begin{array}{l}-0.001 \\
(-2.50)\end{array}$ & $\begin{array}{l}-0.001 \\
(-2.50)\end{array}$ \\
\hline BtoM & & $\begin{array}{r}0.059 \\
(1.42)\end{array}$ & $\begin{array}{r}0.069 \\
(1.57)\end{array}$ & $\begin{array}{r}0.004 \\
(0.83)\end{array}$ & $\begin{array}{r}0.001 \\
(0.18)\end{array}$ \\
\hline Mom & & $\begin{array}{c}0.005 \\
(0.24)\end{array}$ & $\begin{array}{l}-0.011 \\
(-0.57)\end{array}$ & $\begin{array}{r}0.001 \\
(0.35)\end{array}$ & $\begin{array}{c}-0.000 \\
(-0.20)\end{array}$ \\
\hline Skew & & & $\begin{array}{l}-0.127 \\
(-0.20)\end{array}$ & $\begin{array}{r}0.000 \\
(0.13)\end{array}$ & $\begin{array}{r}0.000 \\
(0.46)\end{array}$ \\
\hline Kurt & & & $\begin{array}{r}0.001 \\
(0.02)\end{array}$ & $\begin{array}{r}0.000 \\
(0.43)\end{array}$ & $\begin{array}{l}-0.000 \\
(-0.17)\end{array}$ \\
\hline $\bar{R}^{2}$ & 0.007 & 0.024 & 0.033 & 0.036 & 0.032 \\
\hline
\end{tabular}




\section{Table 7: Option Returns Controlling for Stock Characteristics}

Each month, we first sort stocks into quintiles based on stock characteristics and then, within each quintile, we sort stocks based on the difference between the historical HV and the current IV. The five volatility portfolios are then averaged over each of the five characteristic portfolios. Beta is the stock beta calculated from the market model using last 60 months, Size is the market capitalization, BtoM is the book-to-market, Mom is the last six-month cumulative return, and skewness and kurtosis of stock returns are calculated using the last year's daily data. Breakpoints for all stock characteristics are calculated each month based only on stocks in our sample. The table reports the average return and the associated $t$-statistic of this continuous time-series of monthly returns. The sample period is 1996 to 2005.

\begin{tabular}{lcccccc}
\hline & \multicolumn{7}{c}{ HV-IV quintile } \\
\cline { 2 - 7 } Control & 1 & 2 & 3 & 4 & 5 & $5-1$ \\
\hline \multicolumn{7}{c}{ Panel A: Straddle Returns } \\
\hline Beta & -0.080 & -0.045 & 0.001 & -0.019 & 0.060 & 0.140 \\
& $(-4.40)$ & $(-2.20)$ & $(0.03)$ & $(-0.78)$ & $(2.44)$ & $(6.55)$ \\
Size & -0.078 & -0.038 & 0.009 & 0.009 & 0.082 & 0.160 \\
& $(-4.62)$ & $(-1.77)$ & $(0.42)$ & $(0.40)$ & $(2.94)$ & $(7.20)$ \\
BtoM & -0.085 & -0.040 & 0.008 & -0.010 & 0.084 & 0.169 \\
& $(-4.50)$ & $(-1.67)$ & $(0.33)$ & $(-0.46)$ & $(3.21)$ & $(7.50)$ \\
\multirow{4}{*}{ Mom } & -0.085 & -0.036 & -0.003 & 0.014 & 0.089 & 0.174 \\
& $(-5.05)$ & $(-1.75)$ & $(-0.13)$ & $(0.62)$ & $(3.36)$ & $(8.22)$ \\
\multirow{2}{*}{ Skew } & -0.073 & -0.037 & 0.010 & -0.003 & 0.080 & 0.153 \\
& $(-4.16)$ & $(-1.85)$ & $(0.42)$ & $(-0.12)$ & $(3.02)$ & $(7.34)$ \\
\multirow{2}{*}{ Kurt } & -0.077 & -0.031 & 0.006 & -0.001 & 0.089 & 0.166 \\
& $(-4.60)$ & $(-1.39)$ & $(0.26)$ & $(-0.03)$ & $(3.39)$ & $(7.71)$ \\
\hline
\end{tabular}




\begin{tabular}{|c|c|c|c|c|c|c|}
\hline \multirow[b]{2}{*}{ Control } & \multicolumn{6}{|c|}{ HV-IV quintile } \\
\hline & 1 & 2 & 3 & 4 & 5 & $5-1$ \\
\hline \multicolumn{7}{|c|}{ Panel B: Delta-Hedged Call Returns } \\
\hline Beta & $\begin{array}{l}-0.011 \\
(-5.04)\end{array}$ & $\begin{array}{l}-0.006 \\
(-2.96)\end{array}$ & $\begin{array}{l}-0.002 \\
(-1.01)\end{array}$ & $\begin{array}{c}-0.003 \\
(-1.33)\end{array}$ & $\begin{array}{c}0.004 \\
(1.77)\end{array}$ & $\begin{array}{r}0.015 \\
(7.26)\end{array}$ \\
\hline Size & $\begin{array}{l}-0.011 \\
(-4.83)\end{array}$ & $\begin{array}{r}-0.008 \\
(-3.09)\end{array}$ & $\begin{array}{l}-0.001 \\
(-0.51)\end{array}$ & $\begin{array}{r}0.001 \\
(0.35)\end{array}$ & $\begin{array}{c}0.008 \\
(2.29)\end{array}$ & $\begin{array}{r}0.019 \\
(6.03)\end{array}$ \\
\hline BtoM & $\begin{array}{l}-0.013 \\
(-5.07)\end{array}$ & $\begin{array}{l}-0.007 \\
(-2.73)\end{array}$ & $\begin{array}{l}-0.001 \\
(-0.36)\end{array}$ & $\begin{array}{l}-0.003 \\
(-0.98)\end{array}$ & $\begin{array}{r}0.007 \\
(2.30)\end{array}$ & $\begin{array}{r}0.020 \\
(6.55)\end{array}$ \\
\hline Mom & $\begin{array}{l}-0.012 \\
(-5.10)\end{array}$ & $\begin{array}{l}-0.006 \\
(-2.73)\end{array}$ & $\begin{array}{l}-0.002 \\
(-0.63)\end{array}$ & $\begin{array}{l}0.001 \\
(0.22)\end{array}$ & $\begin{array}{r}0.010 \\
(2.98)\end{array}$ & $\begin{array}{r}0.022 \\
(7.51)\end{array}$ \\
\hline Skew & $\begin{array}{l}-0.011 \\
(-4.40)\end{array}$ & $\begin{array}{l}-0.008 \\
(-3.33)\end{array}$ & $\begin{array}{l}-0.002 \\
(-0.64)\end{array}$ & $\begin{array}{r}0.000 \\
(0.17)\end{array}$ & $\begin{array}{r}0.007 \\
(2.22)\end{array}$ & $\begin{array}{r}0.018 \\
(6.03)\end{array}$ \\
\hline Kurt & $\begin{array}{l}-0.012 \\
(-4.97)\end{array}$ & $\begin{array}{l}-0.006 \\
(-2.36)\end{array}$ & $\begin{array}{l}-0.001 \\
(-0.44)\end{array}$ & $\begin{array}{l}-0.001 \\
(-0.50)\end{array}$ & $\begin{array}{r}0.009 \\
(2.74)\end{array}$ & $\begin{array}{r}0.021 \\
(6.71)\end{array}$ \\
\hline \multicolumn{7}{|c|}{ Panel C: Delta-Hedged Put Returns } \\
\hline Beta & $\begin{array}{l}-0.010 \\
(-5.07)\end{array}$ & $\begin{array}{l}-0.004 \\
(-1.98)\end{array}$ & $\begin{array}{l}-0.001 \\
(-0.58)\end{array}$ & $\begin{array}{l}-0.002 \\
(-0.84)\end{array}$ & $\begin{array}{l}0.006 \\
(2.67)\end{array}$ & $\begin{array}{r}0.015 \\
(8.02)\end{array}$ \\
\hline Size & $\begin{array}{l}-0.009 \\
(-4.40)\end{array}$ & $\begin{array}{l}-0.005 \\
(-2.38)\end{array}$ & $\begin{array}{r}0.001 \\
(0.58)\end{array}$ & $\begin{array}{r}0.002 \\
(0.72)\end{array}$ & $\begin{array}{r}0.008 \\
(2.67)\end{array}$ & $\begin{array}{r}0.017 \\
(6.17)\end{array}$ \\
\hline BtoM & $\begin{array}{l}-0.010 \\
(-4.96)\end{array}$ & $\begin{array}{l}-0.004 \\
(-1.97)\end{array}$ & $\begin{array}{l}-0.001 \\
(-0.26)\end{array}$ & $\begin{array}{l}-0.002 \\
(-0.96)\end{array}$ & $\begin{array}{r}0.008 \\
(2.97)\end{array}$ & $\begin{array}{r}0.018 \\
(7.33)\end{array}$ \\
\hline Mom & $\begin{array}{l}-0.010 \\
(-5.25)\end{array}$ & $\begin{array}{l}-0.003 \\
(-1.15)\end{array}$ & $\begin{array}{r}0.000 \\
(0.02)\end{array}$ & $\begin{array}{r}0.002 \\
(0.69)\end{array}$ & $\begin{array}{r}0.010 \\
(3.44)\end{array}$ & $\begin{array}{r}0.020 \\
(8.12)\end{array}$ \\
\hline Skew & $\begin{array}{l}-0.009 \\
(-4.23)\end{array}$ & $\begin{array}{l}-0.005 \\
(-2.22)\end{array}$ & $\begin{array}{r}0.000 \\
(0.01)\end{array}$ & $\begin{array}{r}0.001 \\
(0.59)\end{array}$ & $\begin{array}{r}0.008 \\
(2.80)\end{array}$ & $\begin{array}{r}0.017 \\
(6.47)\end{array}$ \\
\hline Kurt & $\begin{array}{l}-0.010 \\
(-4.84)\end{array}$ & $\begin{array}{l}-0.003 \\
(-1.44)\end{array}$ & $\begin{array}{r}0.000 \\
(0.13)\end{array}$ & $\begin{array}{r}0.001 \\
(0.22)\end{array}$ & $\begin{array}{r}0.009 \\
(3.16)\end{array}$ & $\begin{array}{c}0.019 \\
(7.01)\end{array}$ \\
\hline
\end{tabular}




\section{Table 8: Impact of Liquidity and Transaction Costs}

We sort stocks independently into deciles based on the difference between the historical HV and the current IV (as in Table 2) and into two groups based on stock options liquidity characteristics. We consider groups based on the average quoted bid-ask spread of all the options series traded in the previous month, as well as based on daily average dollar volume of all the options series traded in the previous month. The returns on options are computed from the mid-point opening price (MidP) and from the effective bid-ask spread (ESPR), estimated to be equal to $50 \%, 75 \%$, and $100 \%$ of the quoted spread (QSPR). The closing price of options is equal to the terminal payoff of the option depending on the stock price and the strike price of the option. If the option expires in the money, exercising the option incurs stock transaction costs too. Panel A reports returns on long-short 10-1 straddle portfolio while Panel B reports returns on long-short 10-1 delta-hedged calls/puts. First row shows the average return while the second row shows the associated $t$-statistic (in parenthesis) of this continuous time-series of monthly returns. The sample period is 1996 to 2005 .

\begin{tabular}{|c|c|c|c|c|}
\hline \multicolumn{5}{|c|}{ Panel A: Returns on 10-1 straddle portfolios } \\
\hline & \multirow[b]{2}{*}{ MidP } & \multicolumn{3}{|c|}{ ESPR/QSPR } \\
\hline & & $50 \%$ & $75 \%$ & $100 \%$ \\
\hline All & $\begin{array}{l}0.225 \\
(7.83)\end{array}$ & $\begin{array}{l}0.140 \\
(4.27)\end{array}$ & $\begin{array}{l}0.107 \\
(3.30)\end{array}$ & $\begin{array}{l}0.075 \\
(2.32)\end{array}$ \\
\hline \multicolumn{5}{|c|}{ Based on average bid-ask spread of options } \\
\hline Low & $\begin{array}{l}0.182 \\
(4.92)\end{array}$ & $\begin{array}{l}0.136 \\
(3.25)\end{array}$ & $\begin{array}{l}0.114 \\
(2.74)\end{array}$ & $\begin{array}{l}0.094 \\
(2.26)\end{array}$ \\
\hline High & $\begin{array}{l}0.277 \\
(7.67) \\
\end{array}$ & $\begin{array}{l}0.142 \\
(3.31) \\
\end{array}$ & $\begin{array}{l}0.099 \\
(2.34) \\
\end{array}$ & $\begin{array}{l}0.059 \\
(1.37) \\
\end{array}$ \\
\hline \multicolumn{5}{|c|}{ Based on average trading volume of options } \\
\hline Low & $\begin{array}{l}0.234 \\
(6.90)\end{array}$ & $\begin{array}{l}0.127 \\
(3.38)\end{array}$ & $\begin{array}{l}0.089 \\
(2.39)\end{array}$ & $\begin{array}{l}0.052 \\
(1.38)\end{array}$ \\
\hline High & $\begin{array}{l}0.226 \\
(5.28) \\
\end{array}$ & $\begin{array}{l}0.151 \\
(3.18) \\
\end{array}$ & $\begin{array}{l}0.126 \\
(2.67) \\
\end{array}$ & $\begin{array}{l}0.103 \\
(2.18)\end{array}$ \\
\hline
\end{tabular}




\begin{tabular}{|c|c|c|c|c|c|c|c|c|}
\hline \multicolumn{9}{|c|}{ Panel B: Returns on 10-1 Delta-Hedged Portfolios } \\
\hline & \multicolumn{4}{|c|}{ Delta-Hedged Call Returns } & \multicolumn{4}{|c|}{ Delta-Hedged Put Returns } \\
\hline & \multirow[b]{2}{*}{ MidP } & \multicolumn{3}{|c|}{ ESPR/QSPR } & \multirow[b]{2}{*}{ MidP } & \multicolumn{3}{|c|}{ ESPR/QSPR } \\
\hline & & $50 \%$ & $75 \%$ & $100 \%$ & & $50 \%$ & $75 \%$ & $100 \%$ \\
\hline All & $\begin{array}{r}0.027 \\
(6.68) \\
\end{array}$ & $\begin{array}{r}0.010 \\
(2.16) \\
\end{array}$ & $\begin{array}{r}0.008 \\
(1.74) \\
\end{array}$ & $\begin{array}{r}0.006 \\
(1.32) \\
\end{array}$ & $\begin{array}{r}0.026 \\
(7.38) \\
\end{array}$ & $\begin{array}{r}0.013 \\
(3.33) \\
\end{array}$ & $\begin{array}{r}0.009 \\
(2.39) \\
\end{array}$ & $\begin{array}{r}0.006 \\
(1.44) \\
\end{array}$ \\
\hline \multicolumn{9}{|c|}{ Based on average bid-ask spread of options } \\
\hline Low & $\begin{array}{c}0.021 \\
(3.63)\end{array}$ & $\begin{array}{r}0.009 \\
(1.40)\end{array}$ & $\begin{array}{r}0.008 \\
(1.21)\end{array}$ & $\begin{array}{r}0.007 \\
(1.04)\end{array}$ & $\begin{array}{r}0.023 \\
(5.24)\end{array}$ & $\begin{array}{c}0.014 \\
(2.77)\end{array}$ & $\begin{array}{c}0.011 \\
(2.30)\end{array}$ & $\begin{array}{r}0.009 \\
(1.85)\end{array}$ \\
\hline High & $\begin{array}{r}0.034 \\
(6.24) \\
\end{array}$ & $\begin{array}{r}0.010 \\
(1.61) \\
\end{array}$ & $\begin{array}{r}0.008 \\
(1.23) \\
\end{array}$ & $\begin{array}{r}0.005 \\
(0.85) \\
\end{array}$ & $\begin{array}{r}0.029 \\
(6.43) \\
\end{array}$ & $\begin{array}{r}0.012 \\
(2.28) \\
\end{array}$ & $\begin{array}{r}0.007 \\
(1.37) \\
\end{array}$ & $\begin{array}{r}0.002 \\
(0.46)\end{array}$ \\
\hline \multicolumn{9}{|c|}{ Based on average trading volume of options } \\
\hline Low & $\begin{array}{r}0.032 \\
(6.66)\end{array}$ & $\begin{array}{r}0.010 \\
(1.92)\end{array}$ & $\begin{array}{r}0.007 \\
(1.44)\end{array}$ & $\begin{array}{r}0.005 \\
(0.97)\end{array}$ & $\begin{array}{r}0.027 \\
(7.13)\end{array}$ & $\begin{array}{r}0.012 \\
(2.68)\end{array}$ & $\begin{array}{r}0.008 \\
(1.68)\end{array}$ & $\begin{array}{r}0.003 \\
(0.68)\end{array}$ \\
\hline High & $\begin{array}{r}0.022 \\
(3.71) \\
\end{array}$ & $\begin{array}{r}0.010 \\
(1.48) \\
\end{array}$ & $\begin{array}{r}0.009 \\
(1.30)\end{array}$ & $\begin{array}{r}0.008 \\
(1.14) \\
\end{array}$ & $\begin{array}{r}0.025 \\
(4.74) \\
\end{array}$ & $\begin{array}{r}0.014 \\
(2.56) \\
\end{array}$ & $\begin{array}{r}0.011 \\
(2.10) \\
\end{array}$ & $\begin{array}{r}0.009 \\
(1.65)\end{array}$ \\
\hline
\end{tabular}




\section{Table 9: Cross-Sectional Model for Predicting Implied Volatility}

Panel A reports the time-series averages of the following Fama and MacBeth (1973) regression ( $t$-statistics adjusted for serial correlation are reported in parenthesis below the coefficient):

$$
\Delta i v_{i, t}=\alpha_{t}+\beta_{1 t} i v_{i, t-1}+\beta_{2 t}\left(i v_{i, t-1}-\overline{i v}_{i, t-12: t-1}\right)+\beta_{3 t}\left(i v_{i, t-1}-r v_{i, t-12: t-1}\right)+\epsilon_{i, t}
$$

where IV is the implied volatility and HV is the historical realized volatility. Lowercase letters denote natural logs. We then estimate a prediction for implied volatility using the following equation:

$$
\Delta \widehat{i v}_{i, t}=\widehat{\alpha}_{t}+\widehat{\beta}_{1 t} i v_{i, t}+\widehat{\beta}_{2 t}\left(i v_{i, t}-\overline{i v}_{i, t-11: t}\right)+\widehat{\beta}_{3 t}\left(i v_{i, t}-r v_{i, t-11: t}\right)
$$

Stocks are sorted into deciles based on the log difference between historical HV and the current IV (as in Table 2). Panel B reports statistics for these portfolios. We report formation-period volatilities and post-formation option returns. Option returns are computed using, as a reference beginning price, the option price computed from Black and Scholes formula using the predicted implied volatility $(\widehat{\mathrm{IV}})$ and, as the closing price, the terminal payoff of the option depending on the stock price and the strike price of the option. All statistics are first averaged across stocks in each decile. The table reports the monthly averages of these cross-sectional averages for each reported number. The sample period is 1996 to 2005.

\begin{tabular}{|c|c|c|c|c|c|c|c|c|c|c|c|}
\hline \multicolumn{12}{|c|}{ Panel B: Portfolios sorted on HV-IV } \\
\hline Decile & 1 & 2 & 3 & 4 & 5 & 6 & 7 & 8 & 9 & 10 & $\overline{10-1}$ \\
\hline \multicolumn{12}{|c|}{ Formation period volatilities } \\
\hline $\mathrm{HV}_{t}$ & 0.437 & 0.454 & 0.451 & 0.468 & 0.477 & 0.502 & 0.525 & 0.551 & 0.595 & 0.729 & - \\
\hline$\widehat{\mathrm{IV}}_{t}$ & 0.548 & 0.504 & 0.479 & 0.479 & 0.473 & 0.482 & 0.486 & 0.493 & 0.505 & 0.542 & - \\
\hline $\mathrm{IV}_{t}$ & 0.603 & 0.529 & 0.493 & 0.486 & 0.474 & 0.478 & 0.480 & 0.480 & 0.485 & 0.504 & - \\
\hline \multicolumn{12}{|c|}{ Post-formation returns } \\
\hline Straddles & -0.013 & -0.009 & -0.030 & -0.019 & -0.014 & -0.022 & -0.014 & -0.047 & -0.044 & 0.024 & 0.037 \\
\hline & $(-0.61)$ & $(-0.40)$ & $(-1.13)$ & $(-0.83)$ & $(-0.54)$ & $(-0.90)$ & $(-0.57)$ & $(-1.95)$ & $(-1.62)$ & $(0.69)$ & $(1.15)$ \\
\hline Delta-hedged & -0.006 & -0.005 & -0.009 & -0.008 & -0.006 & -0.006 & -0.005 & -0.008 & -0.007 & -0.001 & 0.005 \\
\hline Calls & $(-2.11)$ & $(-1.88)$ & $(-2.57)$ & $(-3.08)$ & $(-2.21)$ & $(-1.87)$ & $(-1.55)$ & $(-2.58)$ & $(-1.88)$ & $(-0.28)$ & (1.08) \\
\hline Delta-hedged & -0.002 & -0.001 & -0.002 & -0.002 & -0.001 & -0.001 & 0.001 & -0.004 & -0.002 & 0.004 & 0.006 \\
\hline Puts & $(-0.74)$ & $(-0.29)$ & $(-0.73)$ & $(-0.91)$ & $(-0.48)$ & $(-0.34)$ & $(0.25)$ & $(-1.55)$ & $(-0.79)$ & $(1.05)$ & $(1.53)$ \\
\hline
\end{tabular}

\begin{tabular}{cccc}
\hline \multicolumn{4}{c}{ Panel A: Cross-sectional regression } \\
\hline$i v_{t-1}$ & $i v_{t-1}-\overline{i v}_{t-13: t-2}$ & $i v_{t-1}-r v_{t-12: t-1}$ & $\bar{R}^{2}$ \\
\hline-0.052 & -0.248 & -0.172 & 0.211 \\
$(-6.15)$ & $(-12.02)$ & $(-11.17)$ & \\
\hline
\end{tabular}

